Portland State University

PDXScholar

Civil and Environmental Engineering Master's

Project Reports

Spring 2018

\title{
Evaluating the Applicability of MODFLOW2005 Plus MT3D-USGS: Borden Case Study
}

Linley Mescher

Portland State University

Follow this and additional works at: https://pdxscholar.library.pdx.edu/cengin_gradprojects

Part of the Civil and Environmental Engineering Commons, and the Earth Sciences Commons Let us know how access to this document benefits you.

\section{Recommended Citation}

Mescher, Linley, "Evaluating the Applicability of MODFLOW2005 Plus MT3D-USGS: Borden Case Study" (2018). Civil and Environmental Engineering Master's Project Reports. 42.

https://doi.org/10.15760/CCEMP.41

This Project is brought to you for free and open access. It has been accepted for inclusion in Civil and Environmental Engineering Master's Project Reports by an authorized administrator of PDXScholar. Please contact us if we can make this document more accessible: pdxscholar@pdx.edu. 
EVALUATING THE APPLICABILITY OF MODFLOW PLUS MT3D-USGS:

BORDEN CASE STUDY

BY

LINLEY MESCHER

A research project report submitted in partial fulfillment

of the requirement for the degree of

\author{
MASTER OF SCIENCE \\ IN \\ CIVIL AND ENVIRONMENTAL ENGINEERING
}

Project Advisor:

Gwynn R. Johnson, PhD

Portland State University

(C)2018 


\section{ACKNOWLEDGMENTS}

I would not have been able to complete my Master's degree without the never-ending support of my family and friends. Through the late nights studying, to the stressed out test weeks, I am extremely appreciative of the support and understanding of my ever-changing schedule. My friends from undergrad and my time in Arizona have been supportive from afar, always reminding me I can achieve my goals. My new friends in Portland have kept me sane. My family (all around the world), has kept me grounded and reminded me of what is truly important.

Dr. Gwynn R Johnson has challenged me to push my academic boundaries, which I am very grateful for. I am appreciative of her support both in the classroom, as a mentor, and throughout this project. She was willing and eager to work with me on changing to a project option for the MS degree, and I am glad she pushed me in this direction. Lastly, thanks to Amory Cervarich for keeping me sane during the last few weeks of school. Being able to troubleshoot MODFLOW, learn, and discuss our projects simultaneously has made this project much more enjoyable. 


\begin{abstract}
Groundwater is essential to communities around the world for drinking, industrial, and agricultural purposes. MODFLOW is a modelling program that uses the three-dimensional continuity equation in a finite difference approach to simulate groundwater flow in an aquifer. MT3D-USGS is a MODFLOW package that simulates contaminant transport. This study used MODFLOW2005 with MT3D-USGS to build a model simulating contaminant transport in Borden, Ontario. A study conducted at the Borden site in 1982 injected a solution of eight solutes to test the transport of contaminants over three years. Initial simulations showed similar transport characteristics for chloride and carbon tetrachloride as compared to observed results. Concentration distributions varied significantly between observed and simulated results. MODFLOW with MT3D-USGS proved effective in modeling transport characteristics for the Borden site.
\end{abstract}




\section{TABLE OF CONTENTS}

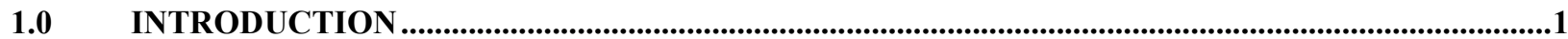

2.0 GROUNDWATER ..............................................................................................................

2.1 MODELING GROUNDWATER ……………………………………………………………………...

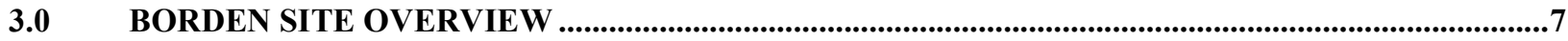

4.0 METHODOLOGY ……..............................................................................................................................

$4.1 \quad$ GROUNDWATER SIMULATION WITH MODFLOW2005 ………………………………..................9

$4.1 .1 \quad$ DISCRETIZATION …………………………………………………………………………...9

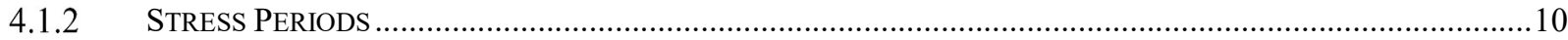

4.1.3 LAYER PROPERTY FLOW PACKAGE ............................................................................................11

4.1.4 CHD -TIME-VARIANT SPECIFIED-HEAD PACKAGE.............................................................................11

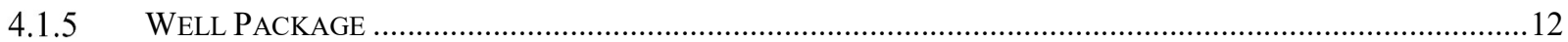

4.2 CONTAMINANT TRANSPORT SIMULATION WITH MT3D-USGS PACKAGE .................................12

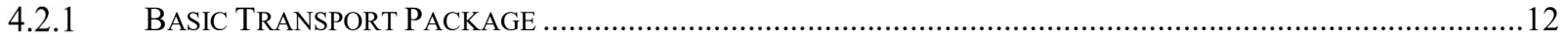

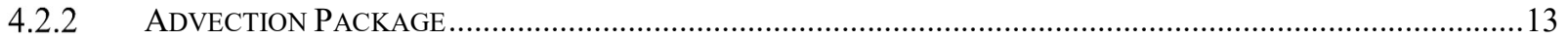

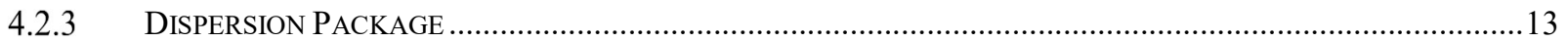

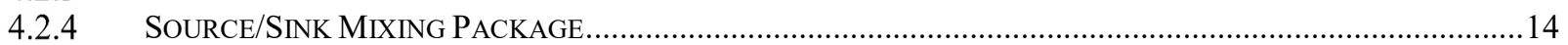

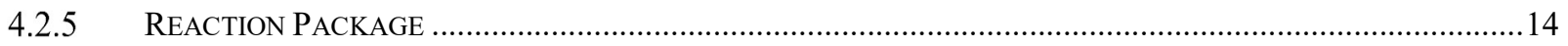

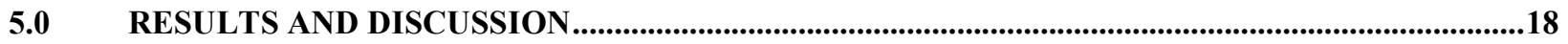

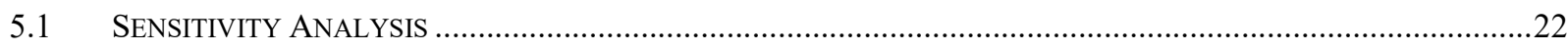

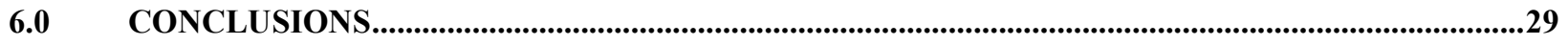

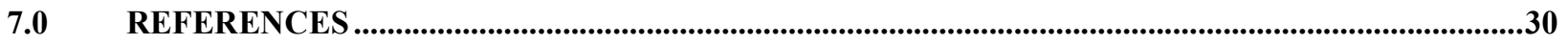

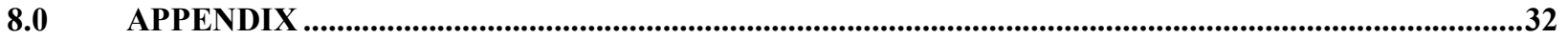




\section{LIST OF TABLES}

Table 1: Summary of packages utilized and associated input parameters 17

Table 2: Experimental Results Compared to Simulation Results for Chloride.........................................................20

Table 3: Experimental Results vs Simulation Results for Chloride............................................................22

\section{LIST OF FIGURES}

Figure 1: Location of multilevel samplers and injection wells (Mackay et al., 1986) ...........................................

Figure 2: Cross sectional view of Borden experimental site (Mackay et al., 1986) .............................................10

Figure 3: Water table map of the Borden site in spring of 1979 (Mackay et al., 1986)..........................................12

Figure 4: Retardation of Chloride vs Carbon Tetrachloride .......................................................................... 15

Figure 5: Experimental results of chloride and carbon tetrachloride plume movement (Mackay et al., 1986) ..........18

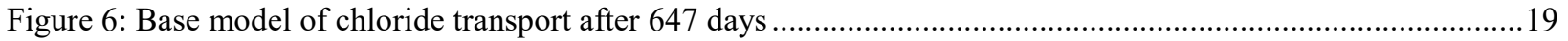

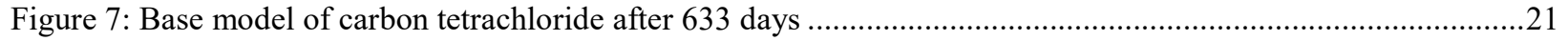

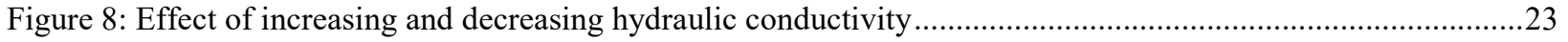

Figure 9: Effect of increasing and decreasing hydraulic conductivity in the y-direction .....................................23

Figure 10: Effect of increasing and decreasing longitudinal dispersivity ........................................................24

Figure 11: Comparing Longitudinal and Horizontal Dispersivity ...................................................................25

Figure 12: Effect of increasing and decreasing the initial head conditions at northern boundary .............................26

Figure 13: Experimental vs MT3D-USGS results of concentration of chloride plume at 462 days ........................27

Figure 14: Cross section of simulated results for chloride plume at 462 days.............................................27

Figure 15: Experimental results of vertical movement of chloride plume..................................................28 


\subsection{INTRODUCTION}

Groundwater is essential to communities around the world for drinking, industrial, and agricultural purposes. Considering the variability in precipitation, groundwater usage rates, and the complexities of subsurface systems, it is important to effectively model aquifers for future management decisions. MODFLOW, a finite-difference flow model written by the United States Geological Survey (USGS) and first introduced publicly in 1987, is a program commonly employed worldwide to model groundwater flow. It uses a finite difference approach to simulate groundwater flow in an aquifer system assuming applicability of a three-dimensional continuity equation describing fluid flow through porous media. The contaminant transport package within MODFLOW (MT3D-USGS) then uses the three-dimensional advection dispersion equation to model contaminant mobility given that previously simulated groundwater flow. This project aims to use the program MODFLOW2005 with its contaminant transport package MT3D-USGS to simulate groundwater flow and contaminant transport within a well-studied aquifer in Borden, Ontario. 


\subsection{GROUNDWATER}

Groundwater is found underground in the void spaces between soil or the pores and cracks in rock. An aquifer holds water that is often used for a purpose by communities, such as drinking water supplies or industrial use. It is estimated that around $50 \%$ of the total US population relies on groundwater as their main source of drinking water (The Groundwater Foundation). It is also very important in farming, where about $64 \%$ of groundwater is used for crop irrigation. Other industrial processes, such as mining and thermoelectric plants, use a significant amount of groundwater. In addition to drinking water and industrial use, groundwater is also the main source for recharging surface bodies of water such as rivers, lakes, and wetlands.

Contamination of groundwater is a major issue throughout the world. The complexity of subsurface systems in the natural environment makes it difficult to quantify and often even to characterize the extent of contamination. Therefore, it is also difficult to effectively clean up. Major sources of groundwater contamination can include septic tanks, landfills, mine waste, leaking pipelines, and runoff that has infiltrated into the ground. These contaminants can be from a variety of processes and can include both organic and inorganic pollutants.

\subsection{Modeling Groundwater}

Modeling groundwater can aid in water management and decision making for communities that rely on groundwater as their source of drinking water. Models can give an idea of the effects that natural or manmade changes could have on a hydrogeologic system. Groundwater generally moves slowly through a soil matrix, which makes it very difficult to 'clean' an aquifer should a contaminant infiltrate into the system. It is important to also model how these contaminants would move in a subsurface system. Additionally, modeling the complex processes controlling long-term transport and fate of these contaminants may help to qualify the mechanisms, either physical and/or chemical, controlling contaminant behavior in the natural subsurface.

In 1980, USGS began developing the program MODFLOW, a computer code that solves the groundwater flow equation. Since then, several versions have been released improving upon the initial program. MODFLOW is a program written in Fortran that uses a finite-difference approach to simulate groundwater flow. It allows the user to define a layer as confined or unconfined and can simulate outside stresses in an aquifer such as recharge, drains, rivers, and wells. The main program has packages, such as the layer property flow package, well package, 
and specified head package, that deals with specific features of the system. This allows the user to examine effects of specific hydrologic features, such as hydraulic conductivity, well injection or extraction rates, or initial head conditions one at a time by turning packages on or off during the simulation.

Hydraulic head is a term used to describe the overall energy content of a fluid and is commonly measured as the elevation of the liquid surface, such as the water table. MODFLOW is based off of the General Continuity Equation and is used to simulate groundwater flow by solving for hydraulic heads. The resulting hydraulic head values depict the elevation of the water table in reference to a datum. The head distributions can be used with the model time period to determine velocity terms of water and solutes through the subsurface system. The contaminant transport package MT3D-USGS is based off of the General Advection Dispersion Equation and is used to simulate subsurface contaminant transport based off of the previously simulated groundwater flow. In this package, the outputs are concentrations of the constituent of interest.

ModelMuse is a graphic user interface (GUI) that is compatible with most MODFLOW versions. This interface gives a 3D visualization of the model, and includes drop down menus for simple selection of the packages that can be used to build complexity to the model. ModelMuse stores calculated head values in a grid-independent fashion, independent of the time periods of interest. This allows the user to go back to make changes to time periods without having to specify the spatial inputs again (ModelMuse user manual). All data is archived, which allows the user to look back on previous simulations.

The GUI ModelMuse is beneficial for new users whom may lack a background in Python or Fortran coding. For example, scripts can be coded using Python or Fortran to develop, run, and post-process models. With the two newest releases of the program, MODFLOW2005 and MODFLOW6, a python package called FloPy can be used to create simulations with scripts. This could be a good approach for someone with a background or desire to gain exposure in Python. Using scripts to run MODFLOW are ideal for conducting sensitivity analysis, drawdown analysis, or a capture analysis as large numbers of simulations can be conducted for small variations in parameters (Bakker et al., 2016).

Groundwater flow simulations in MODFLOW are based on a set of key assumptions built into the program. These assumptions include: the system is anisotropic, there is no change in 
density or in dynamic viscosity of the carrying fluid (water), saturated flow conditions exist, and Darcy's Law can be used to describe the fluid flow through the system. The 3D Continuity Equation combined with Darcy's Law is the basis for describing groundwater flow through a porous media. Equation 1 below is used in a finite difference approach for simulating groundwater flow in MODFLOW.

$$
\frac{\partial}{\partial x}\left(K x \frac{\partial h}{\partial x}\right)+\frac{\partial}{\partial y}\left(K y \frac{\partial h}{\partial y}\right)+\frac{\partial}{\partial z}\left(K z \frac{\partial h}{\partial z}\right)+W=S S \frac{\partial h}{\partial t}
$$

In this equation, $K_{x}, K_{y}$, and $K_{z}$ represent the hydraulic conductivity [L/T] along the x, y, and z coordinate axes, respectively. The variable $h$ represents the potentiometric head [L]. The variable $W$ is a volumetric flux per unit volume representing sources and/or sinks into the system, such as recharge, and is measured in inverse time. The specific storage term, $S_{s}\left[\mathrm{~L}^{-1}\right]$, is the amount of water that a portion of an aquifer releases per unit change in head (Harbaugh, 2015).

In general, the model volume in question is broken down into discrete control volumes. These representative volumes are defined by small cubes in which fluid flows in and out. In order to apply the 3D Continuity Equation, the sum of all fluid flow in and out of each cell within discrete time steps must equal the change in storage within that cell (i.e., a total mass balance approach). The equation used in MODFLOW that represents this change in storage for each discrete control volume (Harbaugh, 2015) is shown below in Equation 2.

$$
\sum Q=S s \frac{\Delta h}{\Delta t} \Delta V
$$

In this equation, $Q$ represents the fluid flow rate into a specific cell. The volume of a hypothetical cell is represented by $V$. All other variables are as defined previously.

Darcy's Law is used to calculate the flow into and out of each cell. The volumetric flow rate is calculated through each face in relation to the cells around it. The flow is calculated between two faces based on a node in the center of each cell. Darcy's Law, as shown in Equation 3, is used to calculate that flow between each cell.

$$
Q=K A \frac{\partial h}{\partial L}
$$

In this equation, $K$ represents a 3D tensor describing hydraulic conductivity variability within the system and all other variables are as defined previously. The change in head from node to node is 
divided by the actual measured distance from node to node, in order to calculate the hydraulic gradient (Harbaugh, 2015). Each grid point has a node in which the head is calculated. Initial head and boundary conditions, such as a lake on the edge of the model with constant head, must be specified. Hydraulic properties of the matrix and any external stresses, such as extraction wells, must be specified to calculate the change in head in the overall system. MODFLOW uses an iterative approach to solve the equations at each time step. The iterative head values eventually converge upon a solution that satisfies the set of equations and defined boundary conditions.

MT3D-USGS is the groundwater solute transport code used in conjunction with the flow terms calculated by MODFLOW. This package has the ability to model steady-state or transient flow, dispersion that varies in the $x, y$, or $z$ direction, and reactions such as sorption in a system (Bedekar et. al, 2016).

When a contaminant is introduced into a subsurface system, several mechanisms affect that contaminant's potential mobility. Advection is a physical process driven by the movement of the dominant fluid flow. Diffusion is a chemical process driven by concentration gradients and defined by Fick's first law and is the movement of a solute from an area of higher concentration to lower concentration. Dispersion is a physical and chemical process often associated with, at minimum, variability in pore size(s), fluid velocity vectors, and intraparticle diffusion. Lastly, reactions such as sorption or chemical decay affect the movement of a solute in a subsurface system. Together, the advection, diffusion, dispersion and reactions of a solute are described by the Advection Dispersion Equation (ADE) in Equation 4 below. This equation describes how a contaminant will move through time and space within the subsurface.

$$
\frac{\partial(\theta C)}{\partial t}=-\left[\frac{\partial\left(J_{x}\right)}{\partial x}+\frac{\partial\left(J_{y}\right)}{\partial y}+\frac{\partial\left(J_{z}\right)}{\partial z}\right]
$$

where $J_{x}, J_{y}$, and $J_{z}$ are functions of advective and diffusive/dispersive fluxes shown by Equation 5 .

$$
J_{x}=\frac{\partial\left(q_{x} C\right)}{\partial x}-\frac{\partial\left[D_{x} \theta \frac{\partial C}{\partial x}\right]}{\partial x}
$$

In this equation, $q$ represents a flux rate of flow $[\mathrm{L} / \mathrm{T}]$, and $D$ is a lumped term dispersion coefficient that is a function of aqueous-phase diffusion, dispersive fluxes often associated with pore size distribution, and intraparticle diffusion. MT3D-USGS uses the ADE in Equation 4 and 
5, with the previously simulated 3D Continuity Equation in Equation 1 to model contaminant transport within a subsurface system. 


\subsection{BORDEN SITE OVERVIEW}

The overall goals of this project are to use MODFLOW2005 and MT3D-USGS to simulate groundwater flow and contaminant transport of an aquifer in Borden, Ontario. This site is used as it is a heavily studied and well documented site that is cited in several contaminant transport textbooks and scientific journals. The initial experiment in 1978 injected $0.7 \mathrm{~m}^{3}$ of a mild chloride (chloride ion) solution, and was monitored over the course of several months. Seven journal articles were published in the Journal of Hydrology. These articles covered topics such as groundwater flow and plume delineation (MacFarlane et al., 1983), using tritium as an indicator of dispersion and recharge (Egboka et al., 1993), cation migration in a dispersion test (Dance and Reardon, 1983), and additional topics. This ground of studies lead to the site being designated as an experimental site for groundwater contamination studies (Cherry et al., 1996).

In 1982, another major experiment was conducted at this site where $12 \mathrm{~m}^{3}$ of water was introduced to the site containing the following solutes: chloride, bromide, bromoform, carbon tetrachloride, tetrachloroethylene, 1,2-dichlorobenzene, and hexachloroethane. The lead scientists and engineers had 275 sampling points, with 14-18 ports on each vertical axis throughout the site (Mackay, 1986). The results from this experiment have been used in several contaminant transport textbooks, and is well documented. Results from this experiment built upon the initial experiment in 1978, and were published in a series of articles in the Water Resources Research Journal. This project includes a simple model based off of this well documented study created in MODFLOW with simulations run to investigate the accuracy and validity of employing MODFLOW2005 plus the contaminant transport package MT3D-USGS. 


\subsection{METHODOLOGY}

To build a simple model of the Borden site, MODFLOW2005 and MT3D-USGS are used within the graphic user interface, ModelMuse. MODFLOW2005 is used to simulate groundwater flow, based upon the General Continuity Equation. MT3D-USGS is the solute transport package that is based upon the Advection Dispersion Equation. When used together, these programs simulate the transport of a solute through a subsurface system.

Within MODFLOW2005 and MT3D-USGS, several packages can be added or removed depending on the system in question. In this project, eight packages are used in total. After discretizing the model and defining the stress periods, the first three packages are used to simulate groundwater flow. These are listed below:

- Layer Property Flow Package - used to specify hydrogeological details about each layer

- Time-Variant Specified-Head Package - used to specify starting and ending heads at various points in the model

- Well Package - used to simulate extraction or injection wells within the system

After running the MODFLOW files, the MT3D-USGS package is activated. Within this component of the modeling for this project, 5 additional packages are used to simulate solute transport. These are listed below:

- Basic Transport Package - used to define constituents of interest and their background concentrations

- Advection Package - previously simulated groundwater flow is incorporated as the advecting fluid component within the ADE (Equation 5)

- Dispersion Package - used to specify primary components of dispersion within a system

- Source/Sink Mixing Package - used to introduce a concentration or mass loading entering the system

- Reaction Package - used to account of reactions such as decay of solutes or sorption of solutes onto soil grains 
The purpose, capabilities, and inputs required of each of these packages are further discussed and outlined in the following sections. Additionally, the inputs in each package that were selected for application of modeling the site conditions and transport behavior measured at Borden are specified. Lastly, a table summarizing all the input parameters is included.

\subsection{GROUNDWATER SIMULATION WITH MODFLOW2005}

\subsubsection{Discretization}

To set up the base model, first the system in question is discretized using the discretization file. This allows the user to define the aquifers overall length and width, as well as the top and bottom elevation. The number of layers, rows and columns are then specified. This creates a 3D grid that is the basis for simulating groundwater flow using the finite difference method.

Results from the natural gradient experiment conducted at the Borden site in 1982 included a top view graphic of the location of the multilevel samplers and injection wells as shown below in Figure 1 (Mackay et al., 1986).

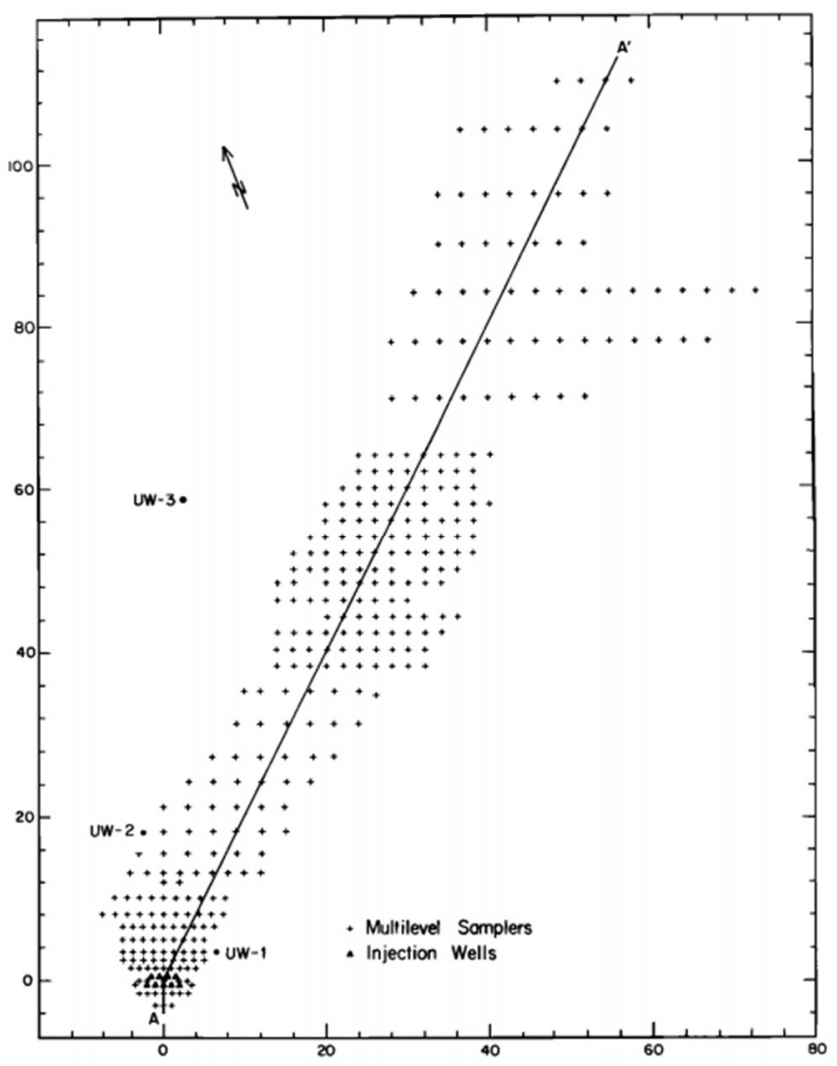

Figure 1: Location of multilevel samplers and injection wells (Mackay et al., 1986) 
This graphic was imported into ModelMuse and used to build the grid upon. This resulted in a 96 by 128 cube grid. Additionally, Mackay et al. (1989) proposed the following cross-sectional view representing average subsurface strata of the experimental zone (see Figure 2).

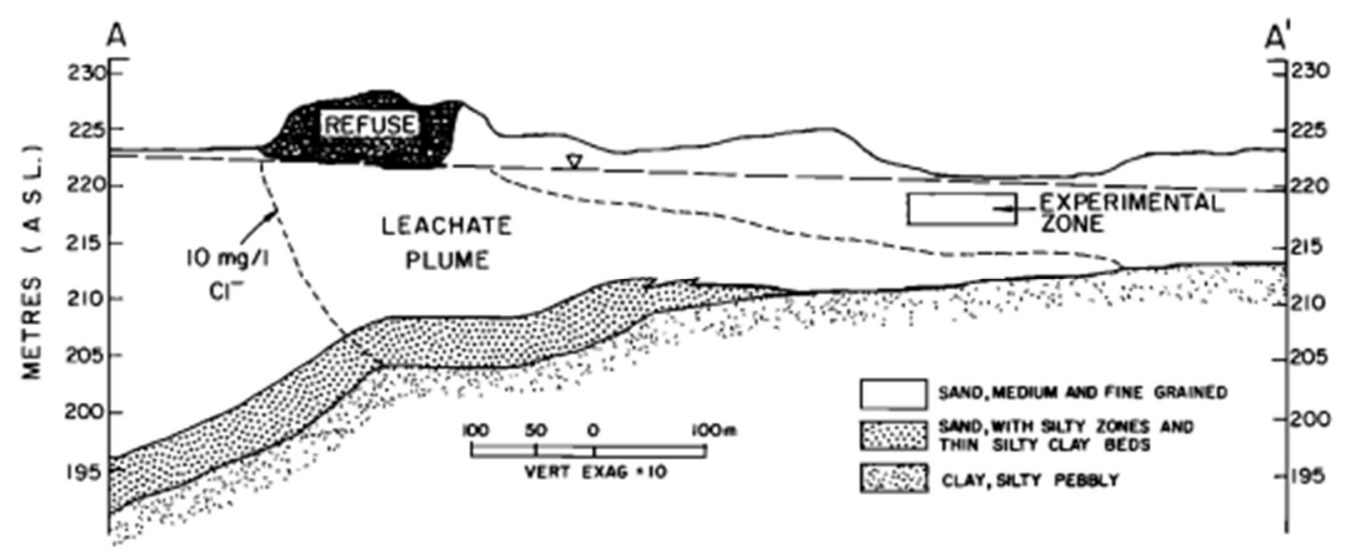

Figure 2: Cross sectional view of Borden experimental site (Mackay et al., 1986)

From this, the grid was expanded to a two layer system. The first layer was defined from the model top at 222 meters above sea level to 212 meters above sea level. This layer is the upper aquifer and is made up of medium and fine grained sand. The second layer was defined from 212 meters to 205 meters above sea level. This is specified as a confining layer and is made up of clay and silt.

\subsubsection{Stress Periods}

The MODFLOW time file allows the user to specify the number of stress periods which is representing a total number of transport steps within a time period. The user can define the start and ending times for each respective stress period. Each stress period can be modeled as transient or steady state. The time unit for all simulations can also be specified as seconds, minutes, hours, days, or years.

In the study conducted at Borden in 1982, a volume of solute was introduced to the system through injection wells over the course of 14.75 hours (Mackay et al, 1986). After the injection, the site was monitored for 3 years. The published results focus mainly on solute transport within the first two years. For the model, two stress periods were used. Stress Period 1 was from time 0 to 14.75 hours, and was modeled as steady state. Stress Period 2 was from 14.75 hours to 2 years, and was also modeled as steady state. 


\subsubsection{Layer Property Flow Package}

The layer property flow package allows the user to specify hydrogeological details about each layer in the aquifer. This includes the ability to change the hydraulic conductivity in the $\mathrm{x}, \mathrm{y}$, and $\mathrm{z}$ directions within each layer. Additionally, the horizontal and vertical anisotropy values can be varied. The user can also denote a specific storage for the overall system.

Estimates of the hydraulic conductivity for the Borden site have been reported by many researchers based on the various studies performed at this site. From the papers published regarding the natural gradient experiment conducted at the Borden site in 1982, an overall geometric mean of the hydraulic conductivity was found to be $9.75 \times 10^{-5} \mathrm{~m} / \mathrm{s}$ (Sudicky et al., 1986). This value was used for both $K_{x}$ and $K_{y}$. The value for $K_{z}$ was estimated as $K_{x} / 10$ (the default setting in MODFLOW), which is a typical ratio of horizontal to vertical hydraulic conductivity (Paradis and Lefebvre, 2012). The value for horizontal anisotropy was estimated as $\mathrm{K}_{\mathrm{y}} / \mathrm{K}_{\mathrm{x}}$ (the default value in MODFLOW). The value for vertical anisotropy was estimated as $\mathrm{K}_{\mathrm{x}} / \mathrm{K}_{\mathrm{z}}$ (also the default value in MODFLOW). Specific storage was set at 0.01 , an average estimate for unconfined aquifers (Freeze and Cherry, 1979).

\subsubsection{CHD -Time-Variant Specified-Head package}

The CHD (time variant specified head package) allows the user to create objects such as wells, lakes, or rivers on the model and specify starting and ending heads at these points. This specifies the boundary conditions for the model. This package can be used to model lakes or rivers with a constant head as boundary conditions.

In the study conducted at the Borden site in 1982, water table maps of the study site were included to show the change in water table seasonally. Regionally, snowmelt and spring rains are the highest from March to June. The water table map for this season is shown below in Figure 3 (Mackay et al, 1986). 


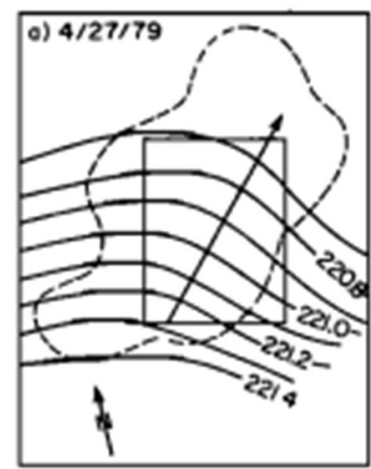

Figure 3: Water table map of the Borden site in spring of 1979 (Mackay et al., 1986)

This water table map was imported into ModelMuse, and head conditions at the boundaries of the study site were imported into the model.

\subsubsection{Well Package}

The well package allows the user to create extraction and injection wells on the model. A point is created on the previously imported/created grid at respective well location(s) and the elevations of the well(s) are specified accordingly. The starting and ending time of pumping must be defined. It should be noted that an extraction well should have a negative pumping rate as fluid is leaving the system. An injection well should have a positive pumping rate as fluid is entering the system.

In the study conducted at Borden in 1982, nine injection wells were used to inject a total of $12 \mathrm{~m}^{3}$ of solution into the system over a 14.75 hour time frame. The injection wells were screened over a vertical of 2.0 to $3.6 \mathrm{~m}$ below ground surface. The nine injection wells received equal and uniform flow of a uniform composition of solution (Mackay et al., 1986). Using the total volume and injection time, a pumping rate for each well was defined at $2.51 \mathrm{e}-5 \mathrm{~m}^{3} / \mathrm{s}$ over the first stress period. The injection wells then had a pumping rate equal to zero (representing a no-flow condition) for the second stress period.

\subsection{CONTAMINANT TRANSPORT SIMULATION WITH MT3D-USGS PACKAGE}

\subsubsection{Basic Transport Package}

The first five packages (as described above) are used in building the base model in which groundwater flow is simulated. The remaining packages are part of the overall MT3D-USGS 
package, which is used to model solute transport. The Basic Transport Package allows the user to first identify the number of species that will modeled and to name them. The initial conditions for the species are specified, such as the constituents of interest and their background concentrations. The porosity for each layer is also defined.

Throughout the history of the Borden field site, a variety of solutes have been studied. In the study conducted in 1982, the total solution was comprised of seven different solutes, two of which were tracers, and the remaining solutes organic compounds. The tracers included chloride ion and bromide ion. The organic solutes included bromoform, carbon tetrachloride, tetrachloroethylene, 1,2-dichlorobenzene, and hexachloroethane. This project included characterization and modeling of two of these solutes: chloride ion and carbon tetrachloride. The initial concentration in the groundwater for each was set to $0 \mathrm{mg} / \mathrm{L}$. The experimental value of porosity used in this model equaled 33\% as reported for this sandy aquifer (Mackay et al., 1986).

\subsubsection{Advection Package}

The advection package must simply be activated in order for MT3D-USGS to simulate solute transport. Advection is the physical process in which the contaminant is moving with fluid in the dominant direction of flow. This is based on the previously simulated groundwater flow, so head distribution results from MODFLOW2005 simulations are brought into the Advection Package within MT3D-USGS.

\subsubsection{Dispersion Package}

The dispersion package allows the user to specify the primary components of dispersion within a system. It may be of interest to note, the mechanisms often associated with dispersion include molecular diffusion, dispersive fluxes associated with pore size distribution, and intraparticle diffusion, each largely causing spreading of solutes in multiple dimensions. Longitudinal dispersivity, horizontal transverse dispersivity, and vertical transverse dispersivity can be defined within each layer allowing for qualification of overall spreading commonly associated with multidimensional fluid flow. The diffusion coefficient, used to qualify spreading due to molecular diffusion, can also be defined for each layer. These components all make up the processes involved in plume spreading. 
In the initial study conducted at the Borden site in 1978, a mild chloride solution was injected into the aquifer and its overall dispersion was qualified as plume movement over several months (Mackay et al., 1986). Results from this field study were used herein to estimate magnitudes of dispersivity. Characterization of plume migration conducted by Sudicky et al. (1983) suggests that longitudinal dispersivity increases from 0.01 at a distance $0.75 \mathrm{~m}$ from the wells to $0.08 \mathrm{~m}$ at $11 \mathrm{~m}$. An estimate of longitudinal dispersivity of $0.08 \mathrm{~m}$ was used in this simulation. The horizontal transverse dispersivity was $0.03 \mathrm{~m}$ at a distance of $11.0 \mathrm{~m}$ from the source. It was found by Sudicky et al. (1983), that vertical transverse dispersivity was weak, and can be estimated by molecular diffusion. In the experiment conducted in 1982, analysis of results from the chloride and bromide tracers resulted in diffusion coefficients of $2.03 \times 10^{-9} \mathrm{~m}^{2} / \mathrm{s}$ and $2.08 \times 10^{-9} \mathrm{~m}^{2} / \mathrm{s}$ respectively (Mackay et al., 1986). The researchers Liu et al. (2011) found that the diffusivity of pure carbon tetrachloride was $1.8 \times 10^{-9} \mathrm{~m}^{2} / \mathrm{s}$. There is little difference in the diffusion coefficients between chloride and carbon tetrachloride, so $2.03 \times 10^{-9} \mathrm{~m}^{2} / \mathrm{s}$ is used in creating the base model for this project.

\subsubsection{Source/Sink Mixing Package}

The source/sink mixing package is used to initiate a concentration or mass loading entering the system. This is done by selecting a previously created object and turning on the SSM package for that object. The starting and ending time of solute injection is specified. The input can either be in terms of concentration or as a mass loading.

In the study conducted on the Borden site in 1982, the solution was injected equally among the 9 injection wells in Stress Period 1. Each well was selected and the SSM package was activated. The starting and ending time for injection followed the same time parameters used in creating Stress Period 1 and Stress Period 2. In Stress Period 1, the concentration of chloride ion was $892 \mathrm{mg} / \mathrm{L}$. The concentration of carbon tetrachloride was $0.031 \mathrm{mg} / \mathrm{L}$. In Stress Period 2, both concentrations were set to 0 (Mackay et al., 1986). This ultimately simulates a typical "pulse injection."

\subsubsection{Reaction Package}

The last package used in this simulation was the reaction package. This package allows the user to account for reactions such as sorption of solutes onto soil grains, or decay of solutes. The 
decay rate constant and sorption parameters are the main parameters that will affect how two different solutes within a solution will ultimately transport at different rates. Each solute being modeled will have the option to define 'Sorption parameter 1', and 'Sorption parameter 2'. Sorption parameter 1 for linear sorption is the distribution coefficient $\left(K_{d}\right)$ and will have units of volume per mass. The value used for Sorption parameter 2 is dependent on the sorption model used. MT3D-USGS has the capability of modeling linear, Freundlich, and Langmuir sorption isotherms (Zheng and Wang, 1999). The bulk density of each layer is also defined within this package.

In this model, the solutes being simulated do not experience first-order reaction kinetics. There is, however, sorption onto the soil grains. The chloride ion is a non-reactive tracer so the Sorption parameter 1 is set to zero. Linear sorption isotherms are used, so Sorption parameter 2 for both chloride and carbon tetrachloride are set to zero. The Sorption parameter 1 for carbon tetrachloride is calculated by taking the ratio of velocity terms to find an estimate for the retardation factor $(\mathrm{R})$. The velocity for chloride and carbon tetrachloride is estimated by using the distance versus time graph in Figure 4, and is found to be 2.38 .

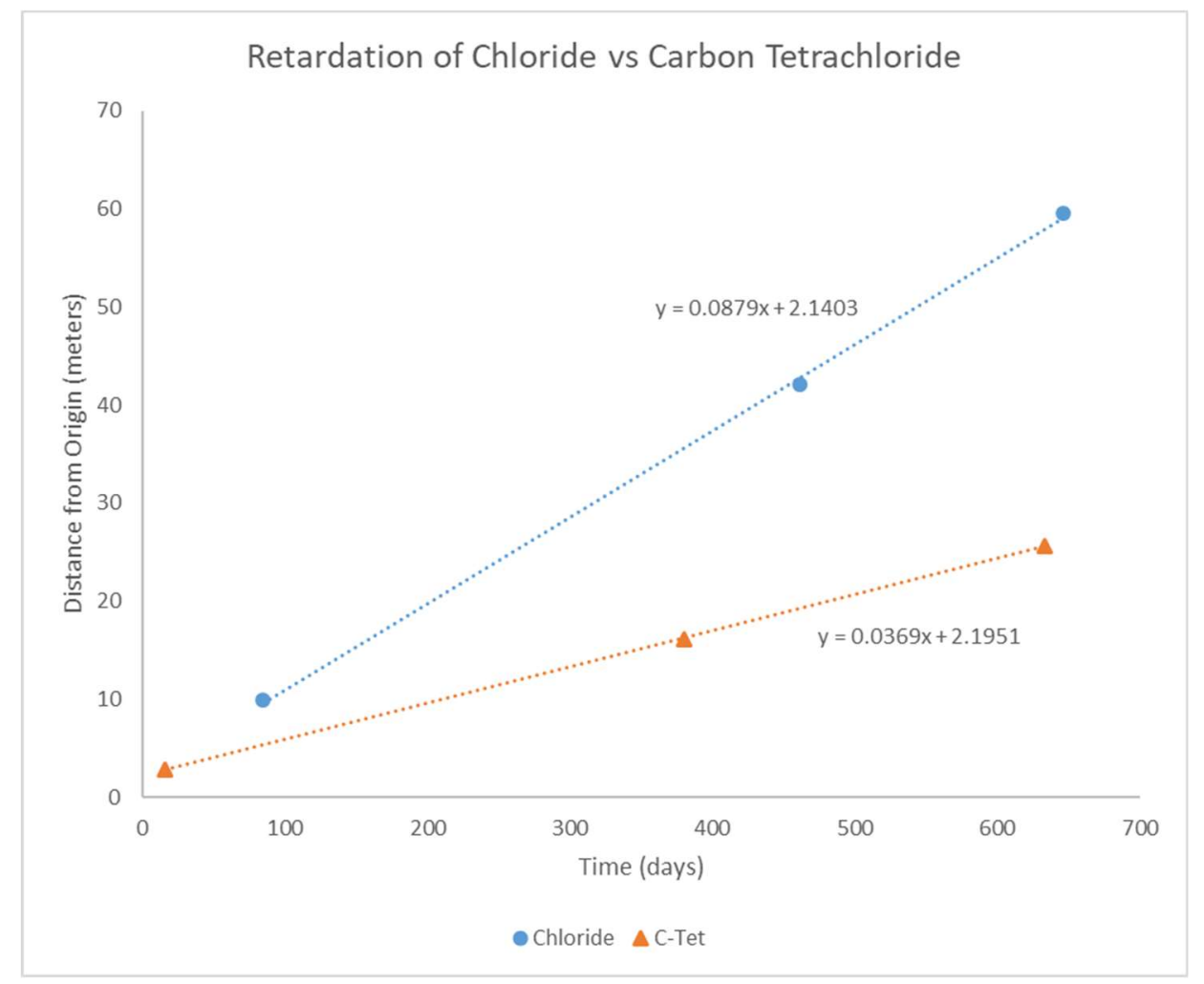

Figure 4: Retardation of Chloride vs Carbon Tetrachloride 
This retardation factor is used with the bulk density and an estimate for water content to calculate a sorption parameter for carbon tetrachloride equal to $2.51 \times 10^{-7} \mathrm{~m}^{3} / \mathrm{g}$. This is within range of typical sorption parameters of carbon tetrachloride reported in the literature (e.g., Wellman et al., 2006). The bulk density used from the results published from the 1982 study equaled $1.81 \mathrm{~g} / \mathrm{cm}^{3}$ (Mackay et al., 1986).

The input parameters outlined in each package are summarized below in Table 1. These base inputs are imported into ModelMuse to run a sensitivity analysis of the experimental parameters. 
Table 1: Summary of packages utilized and associated input parameters

\begin{tabular}{|c|c|}
\hline \multicolumn{2}{|c|}{ MODFLOW2005 } \\
\hline \multicolumn{2}{|l|}{ Grid Discretization } \\
\hline Length & 128 \\
\hline Width & 96 \\
\hline Layers & 2 \\
\hline Aquifer Top & $222 \mathrm{amsl}$ \\
\hline Aquifer Bottom & $205 \mathrm{amsl}$ \\
\hline \multicolumn{2}{|l|}{ Stress Periods } \\
\hline Injection & 0 to 14.75 hour \\
\hline Post Injection & 14.75 hour to 2 years \\
\hline \multicolumn{2}{|l|}{ Layer Property Flow Package } \\
\hline Hydaulic Conductivity $(K x)$ & $9.75 \times 10^{\wedge}-5 \mathrm{~m} / \mathrm{s}$ \\
\hline Ky & Kx \\
\hline$K z$ & $\mathrm{Kx} / 10$ \\
\hline Specific Storage & 0.01 \\
\hline \multicolumn{2}{|l|}{ Basic Package } \\
\hline Head values at boundary & Based off water table maps \\
\hline \multicolumn{2}{|c|}{ MT3DMS } \\
\hline \multicolumn{2}{|l|}{ Basic Transport Package } \\
\hline Species 1 & Chloride \\
\hline Concentration Species 1 & $892 \mathrm{mg} / \mathrm{L}$ \\
\hline Species 2 & Carbon-Tetrachloride \\
\hline Concentration Species 2 & $0.031 \mathrm{mg} / \mathrm{L}$ \\
\hline \multicolumn{2}{|l|}{ Dispersion Package } \\
\hline Longitudinal Dispersivity & $0.08 \mathrm{~m}$ \\
\hline Horizontal transverse dispersivity & $0.03 \mathrm{~m}$ \\
\hline Vertical transverse dispersivity & $10^{\wedge}-10 \mathrm{~m}$ \\
\hline Diffusion coefficient & $2.03 \times 10^{\wedge}-9 \mathrm{~m} 2 / \mathrm{s}$ \\
\hline \multicolumn{2}{|l|}{ Source/Sink Mixing Package } \\
\hline Initial Concentration Species 1 & $0 \mathrm{mg} / \mathrm{L}$ \\
\hline Initial Concentration Species 2 & $0 \mathrm{mg} / \mathrm{L}$ \\
\hline \multicolumn{2}{|l|}{ Reaction Package } \\
\hline Bulk Density & $1.81 \mathrm{~g} / \mathrm{cm} 3$ \\
\hline Sorption Parameter 1 Species 1 & 0 \\
\hline Sorption Parameter 1 Species 2 & $2.51 \times 10^{\wedge}-7 \mathrm{~m} 3 / \mathrm{g}$ \\
\hline Sorption Parameter 2 Species 1 & 0 \\
\hline Sorption Parameter 2 Species 2 & 0 \\
\hline
\end{tabular}




\subsection{RESULTS AND DISCUSSION}

After compiling all necessary input parameters for the packages outlined above, ModelMuse was used to qualify chloride and carbon tetrachloride transport through the subsurface system in Borden. In the experiment conducted in 1982 at the Borden site, 5,000 sampling points were used to collect over 19,900 samples over the course of 3 years. Figure 5 below shows the overview of the chloride tracer plume as well as the carbon tetrachloride plumes (Mackay et al., 1986). Results from the ModelMuse simulations are compared to these plume overview figures to analyze the validity of employing MODFLOW and MT3D-USGS in this simple experimental aquifer.
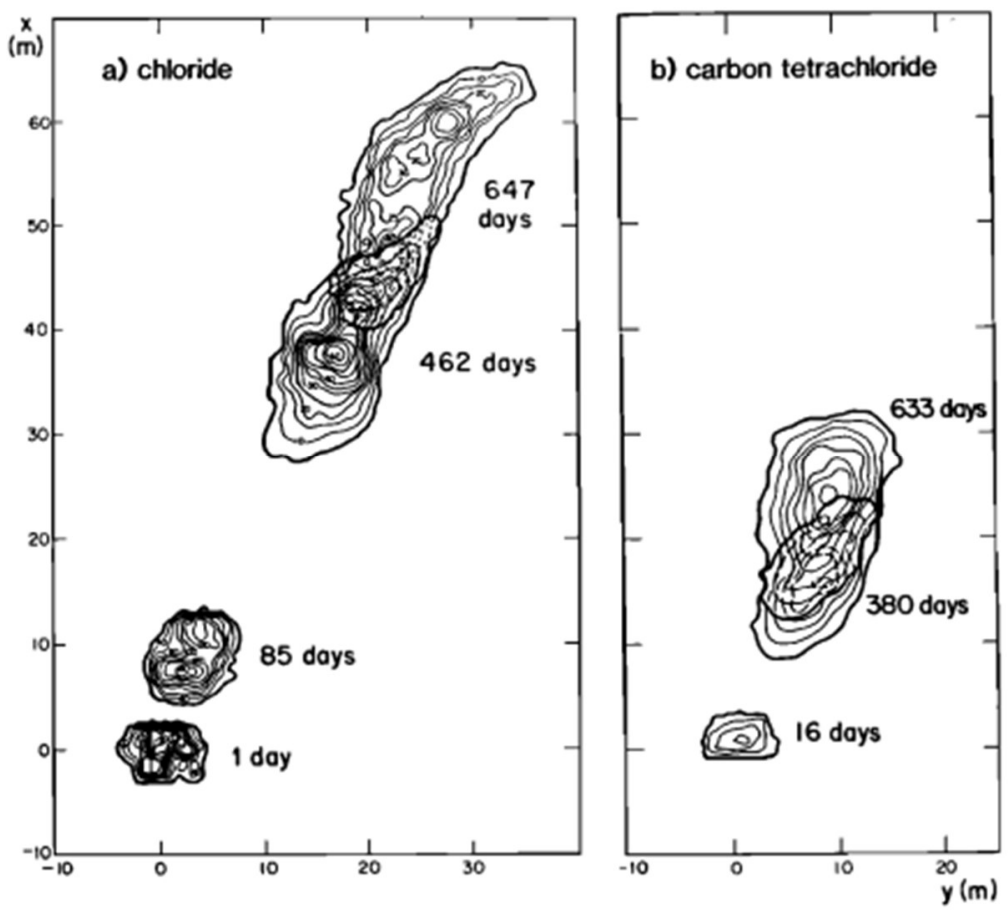

Figure 5: Experimental results of chloride and carbon tetrachloride plume movement (Mackay et al., 1986)

The base parameters highlighted in Table 1 produced the movement of the chloride tracer shown below in Figure 6 . 

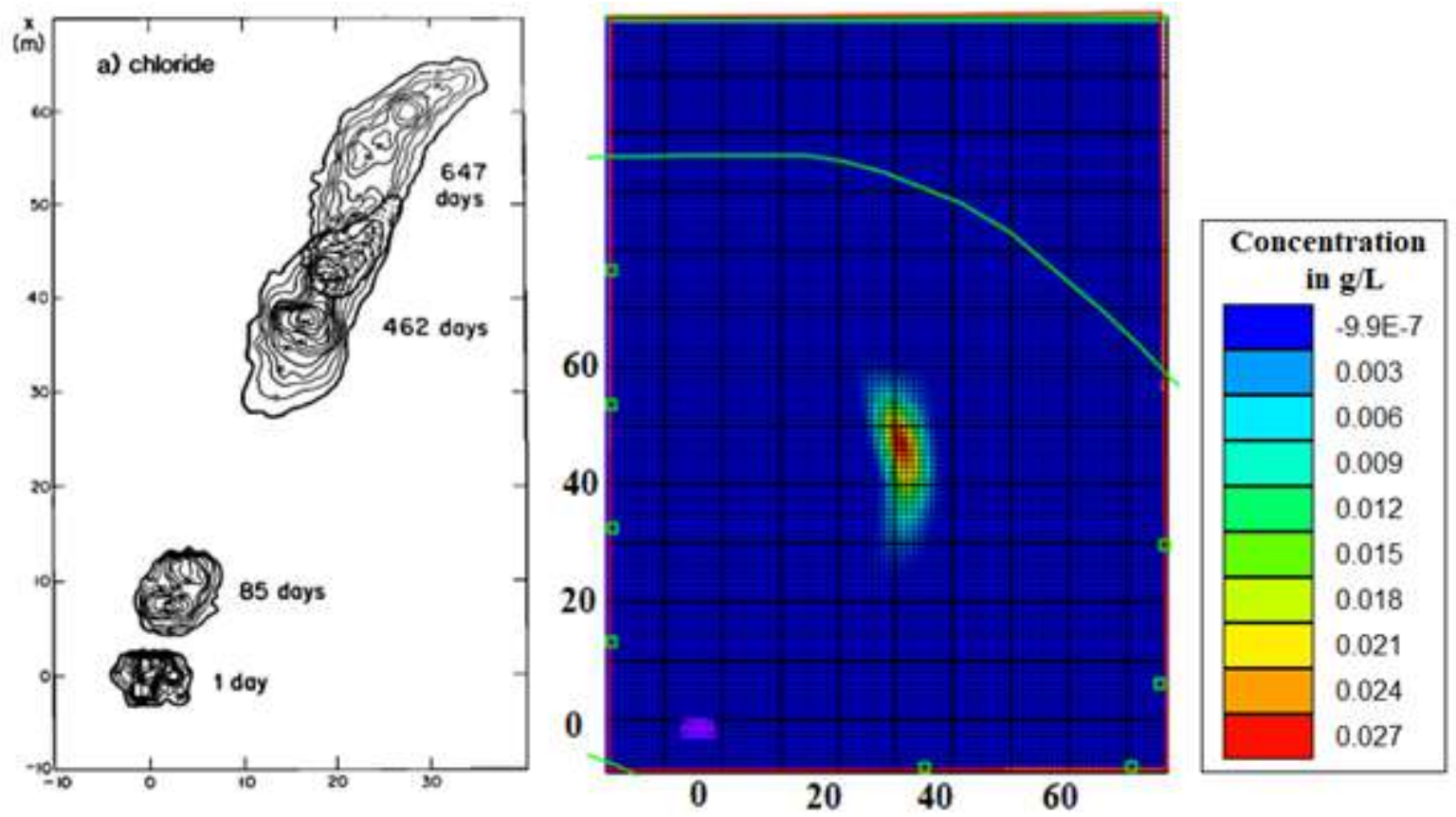

Figure 6: Base model of chloride transport after 647 days

From this image, it can be seen that the plume moves a similar distance from the injection wells when compared to experimental results. The direction of the plume has some variability, possibly due to variation in initial head conditions. One water table map was used to set initial head conditions for the entire simulation period. However, in the real world, water table levels will vary seasonally. This simplification in creating the base model could be impacting the difference in direction in which the plume is moving.

Experimental results from the study conducted by Mackay et al. (1986) are used to estimate a total travel distance from the injections wells to the center of the plume. Similarly, simulation results presented in Figure 6 are used to find a total travel distance from the injection wells to the center of the plume. The three time periods of interest are 85 days, 462 days, and 647 days. The total travel distance for each of these time periods, as well as the percent difference between experimental and simulation results is shown in Table 2. 
Table 2: Experimental Results Compared to Simulation Results for Chloride

\begin{tabular}{|c|c|c|c|}
\hline \multicolumn{4}{|c|}{ Base Model of Chloride } \\
\hline & Test Results & $\begin{array}{c}\text { Simulation } \\
\text { Results }\end{array}$ & $\begin{array}{c}\text { Percent } \\
\text { difference }\end{array}$ \\
\hline Time period (days) & 85 & 85 & \multirow[b]{2}{*}{9.83} \\
\hline $\begin{array}{l}\text { Distance of center of } \\
\text { plume from origin }(\mathrm{m})\end{array}$ & 9.85 & 10.82 & \\
\hline Time period (days) & 462 & 462 & \multirow[b]{2}{*}{2.93} \\
\hline $\begin{array}{l}\text { Distance of center of } \\
\text { plume from origin }(\mathrm{m})\end{array}$ & 42.05 & 43.28 & \\
\hline Time period (days) & 647 & 647 & \multirow[b]{2}{*}{0.83} \\
\hline $\begin{array}{l}\text { Distance of center of } \\
\text { plume from origin }(\mathrm{m})\end{array}$ & 59.51 & 60.00 & \\
\hline
\end{tabular}

In this table, the percent difference for the first time period of 85 days is higher than the later time periods. In the initial study conducted at Borden by Sudicky et al. (1983), it was suggested that longitudinal dispersivity values for the site were $0.08 \mathrm{~m}$ at a distance greater than $10 \mathrm{~m}$ from the injection source. Dispersivity values closer to the injection point were found to be $0.01 \mathrm{~m}$. For the input parameters, longitudinal dispersivity was defined as $0.08 \mathrm{~m}$, potentially explaining the larger percent difference for the first time period.

The base parameters highlighted in Table 1 produced the movement of the carbon tetrachloride shown below in Figure 7. 

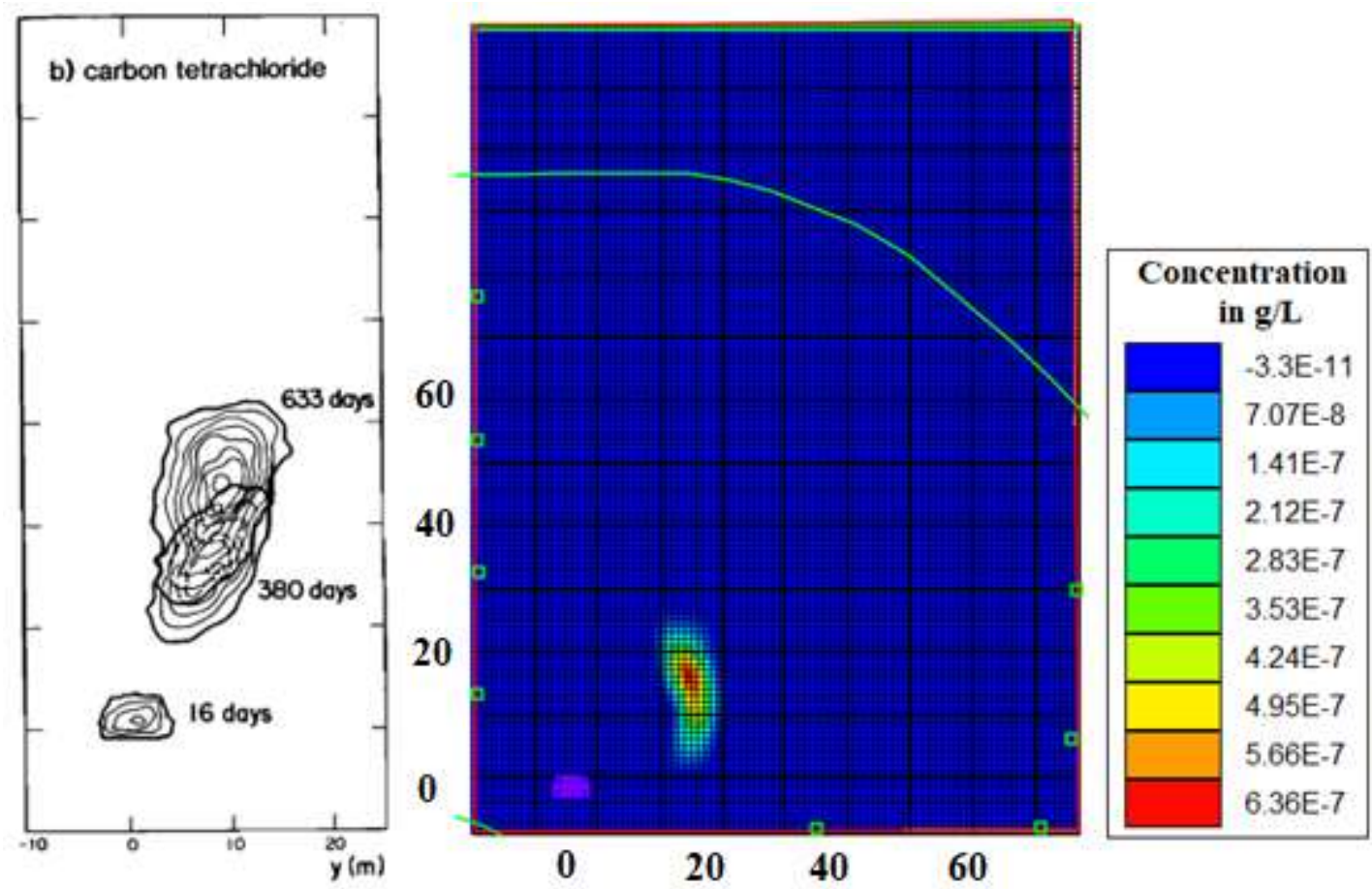

Figure 7: Base model of carbon tetrachloride after 633 days

As outlined in the Methods section, the retardation factor for carbon tetrachloride was found to be 2.38. From Figure 7, it can be seen that the solute is retarded in mobility in comparison to the chloride tracer, as expected based on calculated retardation factors. The plume itself is comparable in size due to spreading. The three time periods of interest are 16 days, 380 days, and 633 days. The total travel distance for each of these time periods, as well as the percent difference between experimental and simulation results is shown in Table 3. 
Table 3: Experimental Results vs Simulation Results for Chloride

\begin{tabular}{|c|c|c|c|}
\hline \multicolumn{4}{|c|}{ Base Model of C-Tet } \\
\hline & Test Results & $\begin{array}{c}\text { Simulation } \\
\text { Results }\end{array}$ & $\begin{array}{c}\text { Percent } \\
\text { difference }\end{array}$ \\
\hline Time period (days) & 16 & 16 & \multirow[b]{2}{*}{20.94} \\
\hline $\begin{array}{l}\text { Distance of center of } \\
\text { plume from origin }(\mathrm{m})\end{array}$ & 2.83 & 2.24 & \\
\hline Time period (days) & 380 & 380 & \multirow[b]{2}{*}{6.70} \\
\hline $\begin{array}{l}\text { Distance of center of } \\
\text { plume from origin }(\mathrm{m})\end{array}$ & 16.12 & 17.20 & \\
\hline Time period (days) & 633 & 633 & \multirow[b]{2}{*}{2.41} \\
\hline $\begin{array}{l}\text { Distance of center of } \\
\text { plume from origin }(\mathrm{m})\end{array}$ & 25.63 & 26.25 & \\
\hline
\end{tabular}

In this table, the percent difference for the first time period of 16 days is higher than the later time periods. This is similar to that of the chloride results, and is likely also attributed to the longitudinal dispersivity value used in the base model.

\subsection{Sensitivity Analysis}

A sensitivity analysis was conducted to investigate the impact of changing various input parameters on model results. Altering the horizontal transverse dispersivity, the vertical transverse dispersivity, as well as the diffusion had little impact on overall movement or spreading of the plume at the end of the simulation period. Bulk density also had little impact. Increasing and decreasing horizontal hydraulic conductivity by one order of magnitude greatly impacted how far the plume moved along the axis of dominant fluid flow and is shown below in Figure 8. 

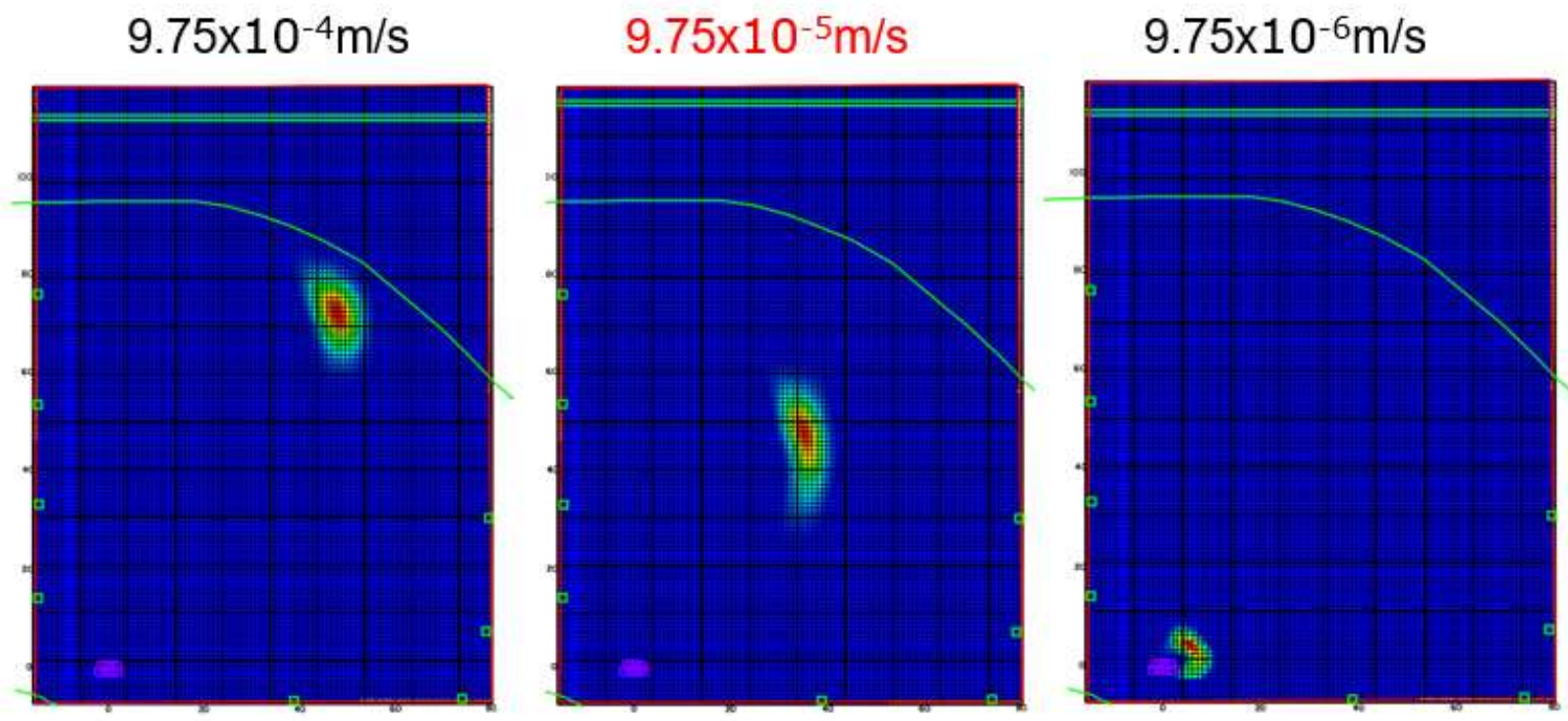

Figure 8: Effect of increasing and decreasing hydraulic conductivity

In the base simulation, a hydraulic conductivity was used of $9.75 \times 10^{-5} \mathrm{~m} / \mathrm{s}$. Hydraulic conductivity is used to describe the ability of a material to transmit a fluid through its pore spaces. When the hydraulic conductivity was increased, the plume moved farther in the simulation period. Conversely, when the hydraulic conductivity was decreased, the plume movement was minimal in the total study period. These results are as to be expected. The default in MODFLOW is to set $\mathrm{K}_{\mathrm{y}}$ $=\mathrm{K}_{\mathrm{x}}$. In Figure 9 below, only $\mathrm{K}_{\mathrm{y}}$ values were altered.
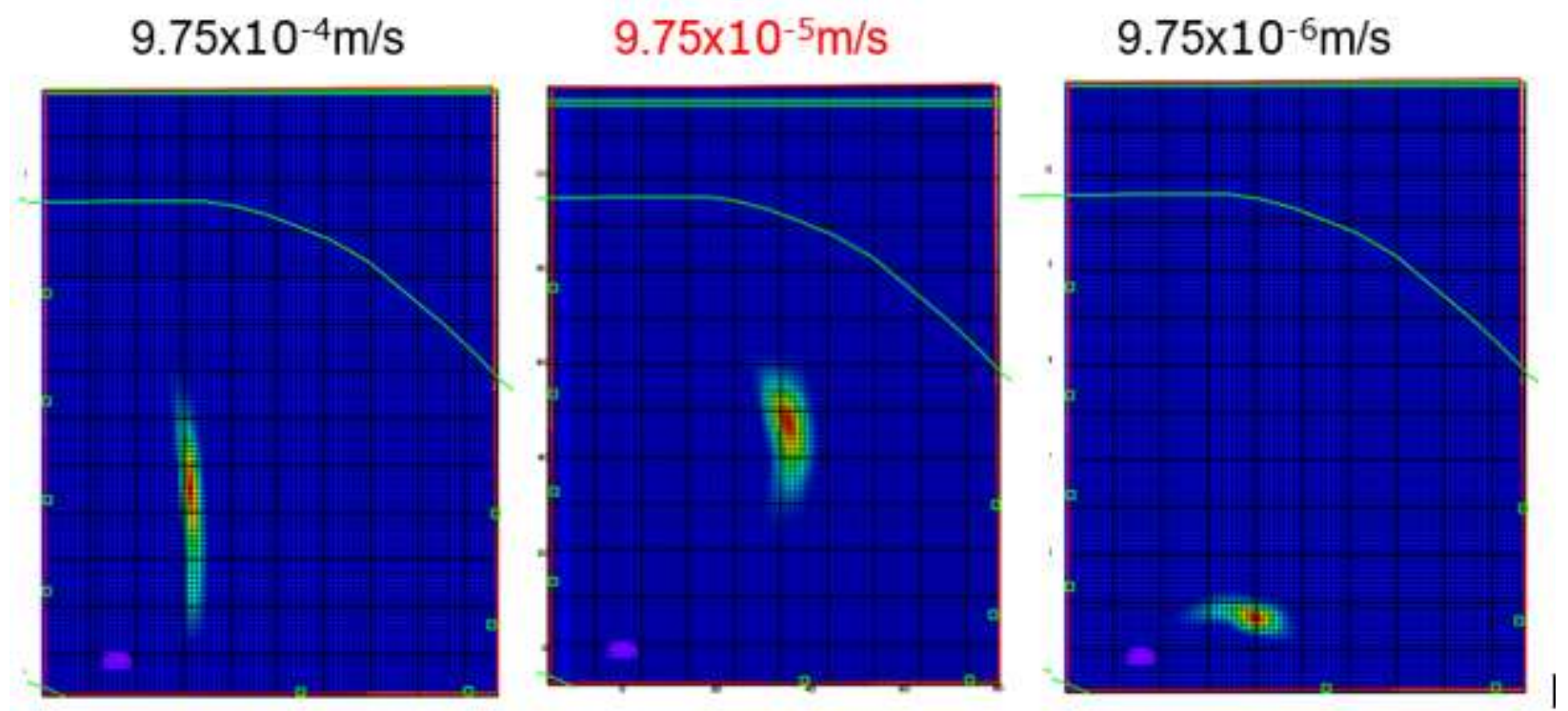

Figure 9: Effect of increasing and decreasing hydraulic conductivity in the y-direction 
From these simulations, it can be seen that the $\mathrm{x}$ and $\mathrm{y}$ coordinate axes are not in line with the direction of fluid flow. Rather, $\mathrm{x}$ is the axis from left to right, and $\mathrm{y}$ is the axes from top to bottom. When the hydraulic conductivity in the y-direction only is increased, the plume is spread much longer in the y axis (top to bottom of the model plan view). When the hydraulic conductivity in the y-direction only is decreased, the plume has little movement along the y axis (top to bottom of the model plan view).

Longitudinal dispersivity values were also altered to investigate the effect on plume spreading and movement. These results are shown below in Figure 9.
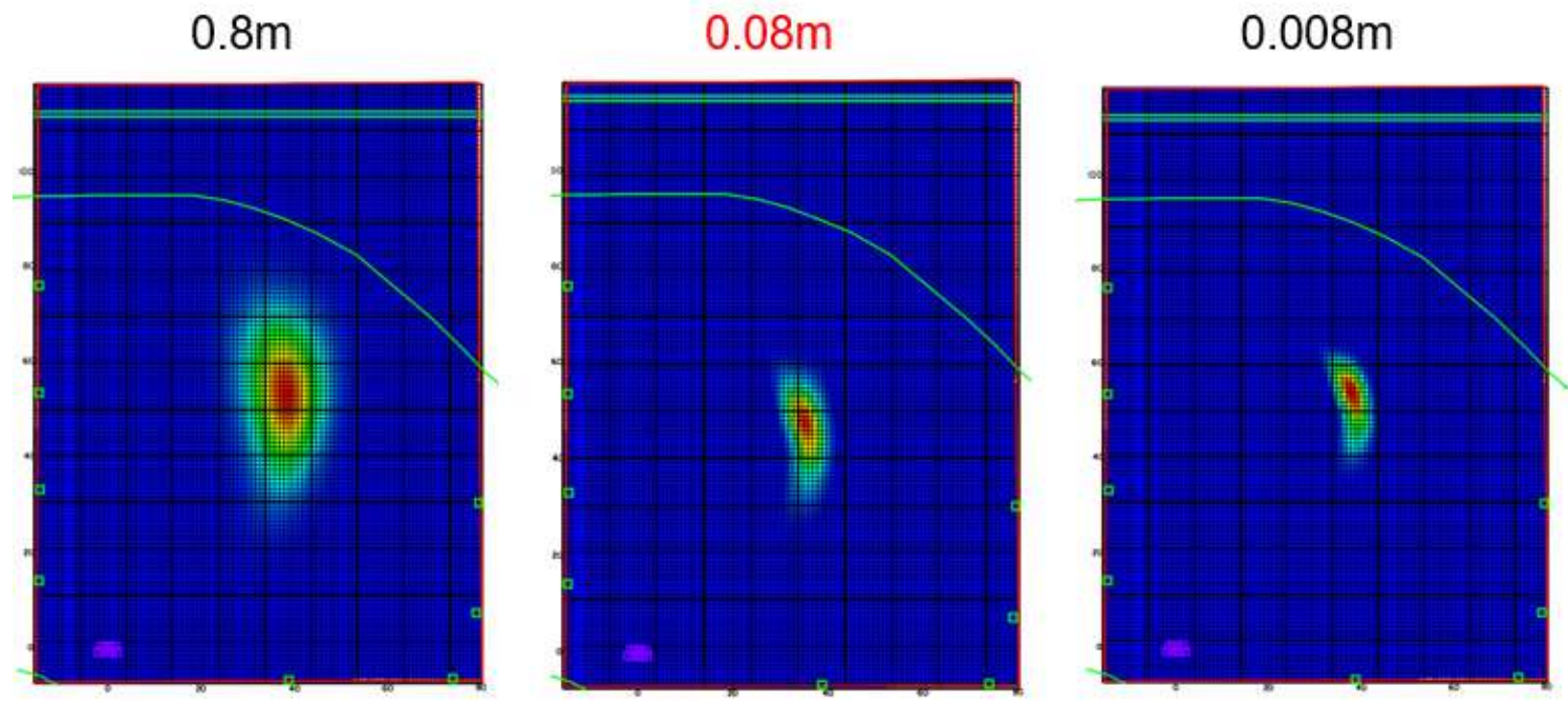

Figure 10: Effect of increasing and decreasing longitudinal dispersivity

In the base model, a longitudinal dispersivity value of $0.08 \mathrm{~m}$ was used. Increasing the longitudinal dispersivity by one order of magnitude had a large impact on the spreading of the overall plume. Decreasing this parameter conversely had a large impact on the lack of spreading of the overall plume.

Longitudinal dispersivity is the spreading of the plume with the dominant direction of flow. Horizontal dispersivity is the spreading of the plume perpendicular to that dominant direction of flow. These two parameters are compared and results are shown in Figure 11. 


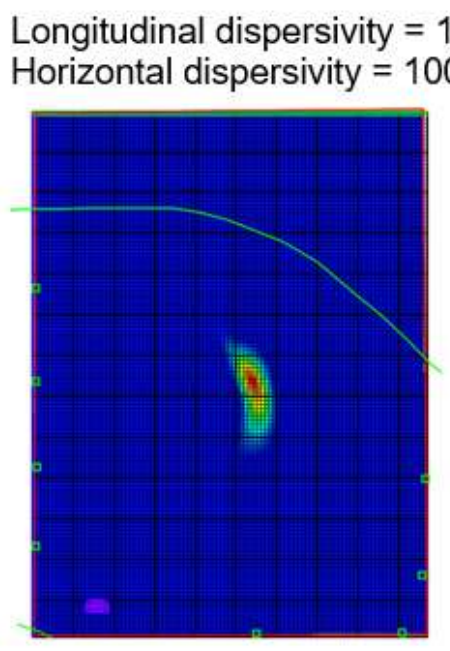

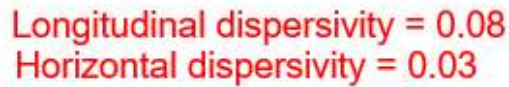

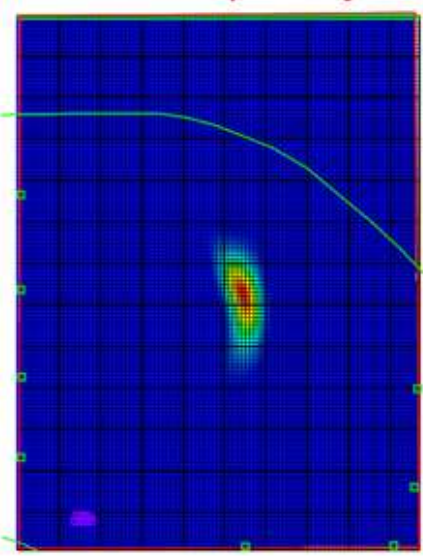

Longitudinal dispersivity $=10$

Horizontal dispersivity $=1 \times 10^{-6}$

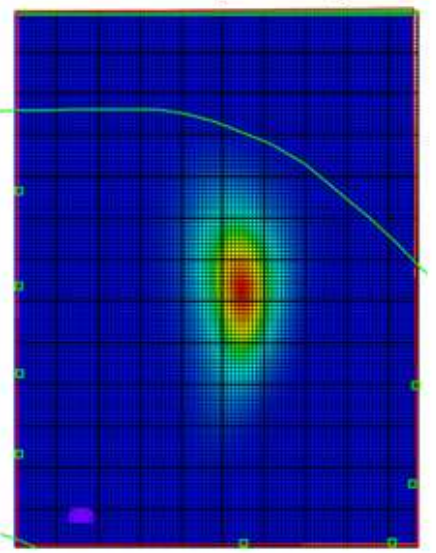

Figure 11: Comparing Longitudinal and Horizontal Dispersivity

In the first simulation, the longitudinal dispersivity was decreased significantly, and horizontal was increased significantly. This resulted in little change to the base model. In the second simulation, the plume was spread more in both the $\mathrm{x}$ and $\mathrm{y}$ directions. Longitudinal dispersivity should be spreading in the direction of dominant fluid flow, so it would be expected that the plume should be oriented more to the north-east, parallel with the dominant fluid flow. However, because it is not, the axis of this parameter needs to be adjusted. The longitudinal and horizontal dispersivities do not appear to be consistent with the actual groundwater flow. These parameters should be further developed to improve the model.

The curved green line on the simulations results depicts an equipotential line. This is one of the initial head conditions set in the model, and is based off of a water table map of the area. This elevation in head was altered slightly to assess the impact of changing initial head conditions, shown in Figure 10. 

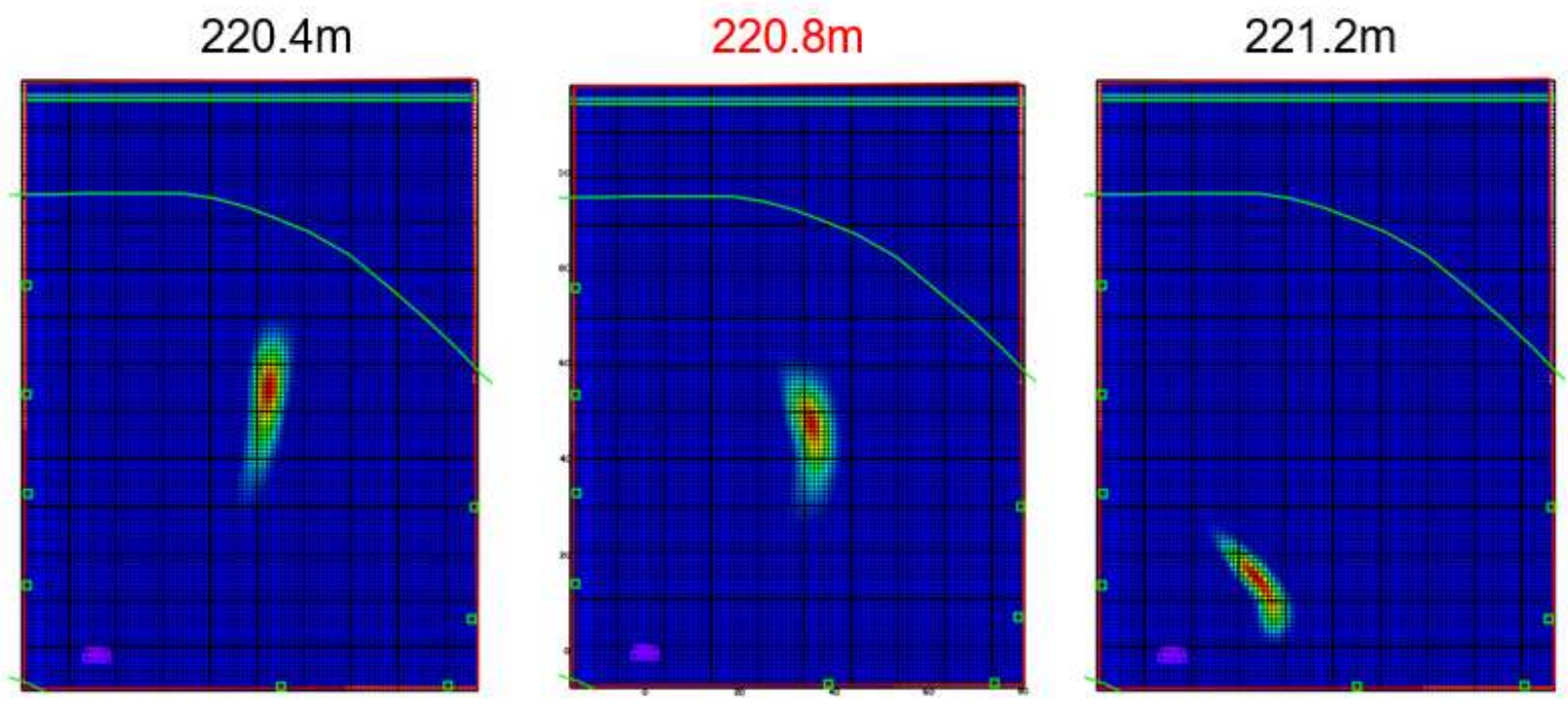

Figure 12: Effect of increasing and decreasing the initial head conditions at northern boundary

The initial head at this line was set to 220.8 meters above sea level in the base model. A simulation was conducted decreasing the head condition by $0.4 \mathrm{~m}$. This essentially is creating a larger hydraulic gradient, or a steeper slope in water table. This results in the plume moving slightly farther in the simulation period. This is as to be expected because the advecting fluid is having a larger impact on the transport of the contaminant. The steeper slope in water table also appears to result in slightly less spreading than compared to the base model. However, it is expected that the plume should have increased spreading when the velocity of the fluid increases. When the initial head was increased by $0.4 \mathrm{~m}$, the hydraulic gradient is decreased, which creates a less steep slope in water table. This results in the plume remaining relatively close to the injection source over the simulation period. These results show the large impact that advection attributed to groundwater flow has on the transport of contaminants.

Simulations for both chloride and carbon tetrachloride resulted in similar overall transport characteristics when compared to experimental results. However, concentrations within these simulated plumes are smaller than measured concentrations in the 1982 study conducted (Mackay et al., 1986). After 462 days, the chloride plume had concentrations ranging from $60 \mathrm{mg} / \mathrm{L}$ to $10 \mathrm{mg} / \mathrm{L}$. Simulations run with MT3D-USGS suggest that at this same time step, concentrations of the plume range between $32.3 \mathrm{mg} / \mathrm{L}$ to $3.6 \mathrm{mg} / \mathrm{L}$. Figure 11 below shows the experimental concentration contours, alongside the simulation results for the same time step. 

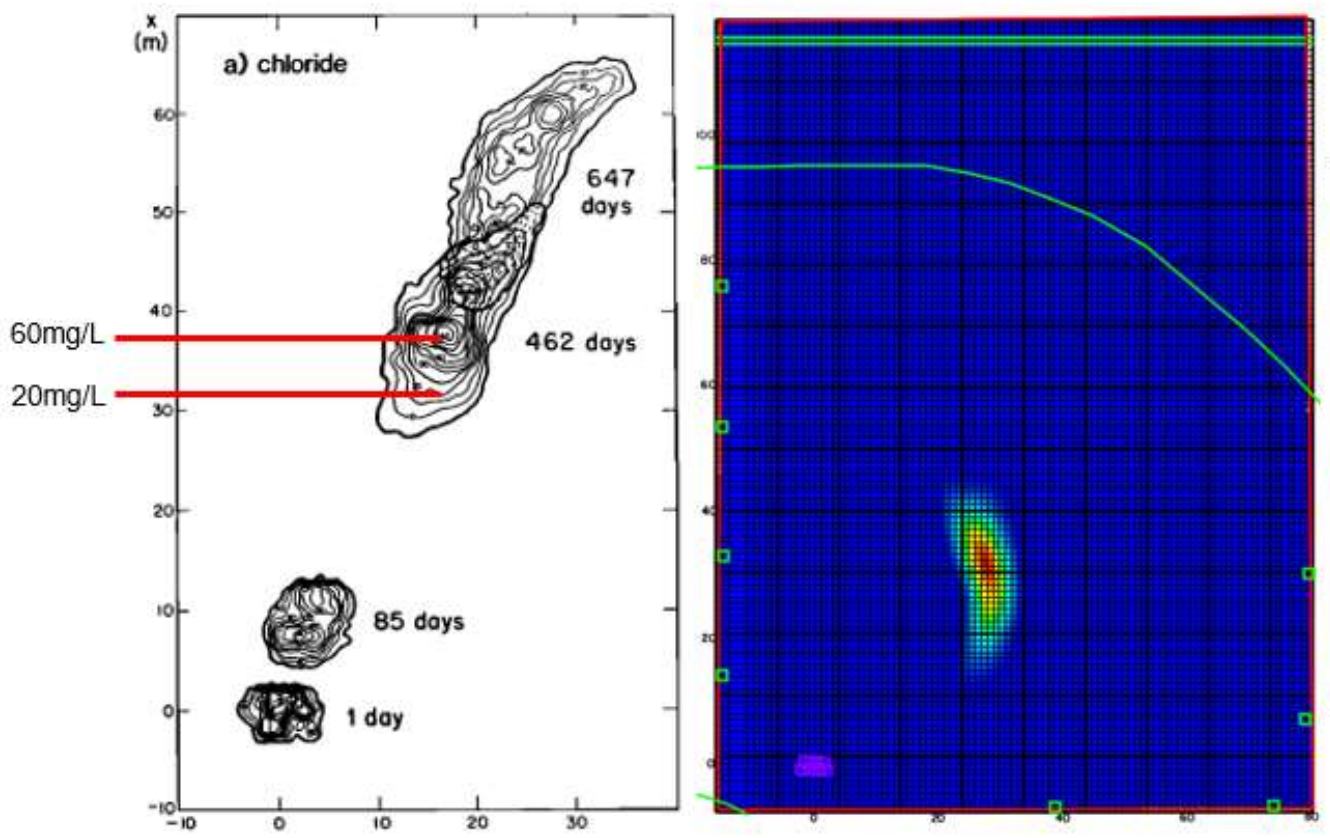

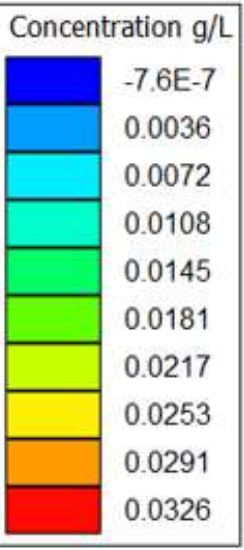

Figure 13: Experimental vs MT3D-USGS results of concentration of chloride plume at 462 days

This difference in concentrations could be the result of the model simulating the plume distributing evenly across the vertical axis (i.e., through the thickness of the aquifer system). Though initially the solution was injected at 2.0 to $3.6 \mathrm{~m}$ below the ground surface, results show an equal cross section of contamination across the sandy aquifer, presented in Figure 12.

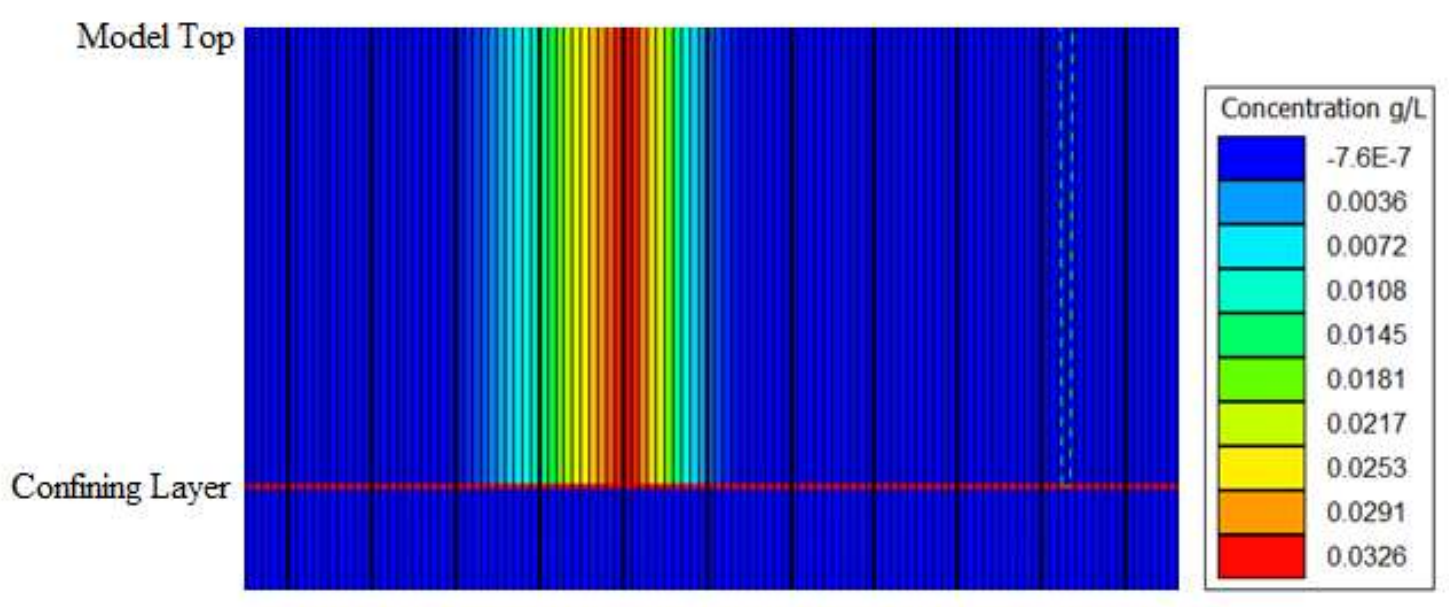

Figure 14: Cross section of simulated results for chloride plume at 462 days 
Actual experimental results found that the plume moves closer to the bottom of the aquifer, as shown in Figure 13. This is as to be expected due to the naturally sloping water table.

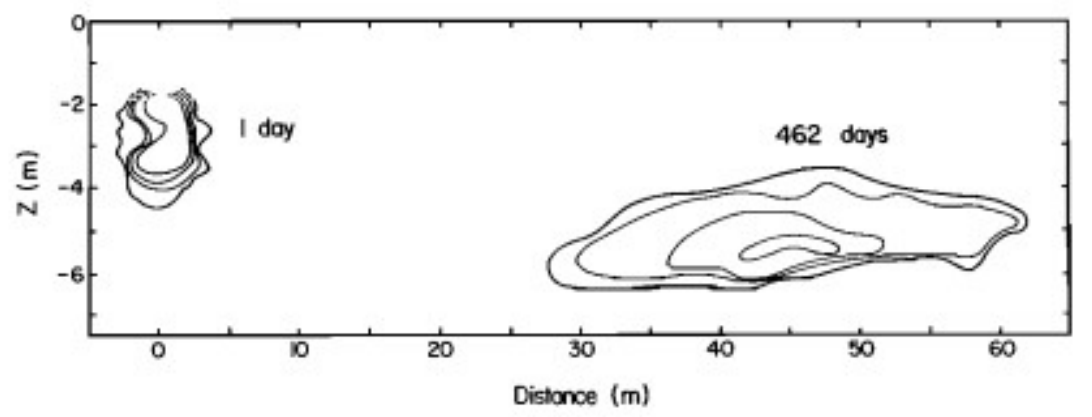

Figure 15: Experimental results of vertical movement of chloride plume

In order to effectively model transport in the vertical plane, vertical anisotropy should be incorporated into the model. Changes in $\mathrm{K}_{\mathrm{z}}$ have a small effect in concentration distributions, however the plume is spread even across the vertical. In order to improve this model further, a vertical anisotropy component should be investigated. The upper aquifer is comprised of sand so is relatively homogeneous. However, this parameter should be further investigated in order to address the issue of the plume spreading evenly across the vertical axis.

Using the input parameters outlined in Table 1 in MODFLOW2005 and MT3D-USGS, a user can produce solute transport results similar to experimental results from the 1982 study conducted in Borden. These input parameters set a basis to easily manipulate parameters individually. Transport characteristics of simulation results are similar to experimental results. Concentration distributions of simulation results are smaller than experimental results. In analyzing these results, it is concluded that MODFLOW2005 plus MT3D-USGS can be used as an effective tool to model contaminant transport in a simple subsurface system. 


\subsection{CONCLUSIONS}

The Borden site is a well-studied site with regards to groundwater flow and contaminant transport. Data is readily available concerning the geological properties of the aquifer. In this paper, the results of simulations obtained using MODFLOW2005 and MT3D-USGS are compared to solute transport data measured for this relatively simple aquifer. Using input parameters outlined from a study conducted in 1982, modeled solute plumes for a chloride tracer closely match experimental results. Modeled solute plumes for carbon tetrachloride appeared more retarded in experimental results than initial simulation results.

To further improve the accuracy of this model, vertical anisotropy should be investigated further. Simulation results show an even spreading of the contaminant across the vertical, resulting in decreased concentration distributions. Longitudinal dispersivity is not consistent with the dominant direction of fluid flow, so all dispersivity values need to be oriented on the correct axis. Additionally to improve the model, more specific estimates of initial and ending head values should be used. One estimate was used to set the boundary conditions of the aquifer, but seasonal water table changes were not taken into effect. Accounting for these fluctuations in the water table could more accurately depict the direction and distance in which a contaminant plume may move. This site has been well studied since the initial experiment conducted by Sudicky et al. (1983), with a variety of solutes. Using data from these other studies, additional solutes could be simulated in this system to determine the validity and accuracy of the model.

The Borden site in Ontario is a well-studied site in regards to groundwater flow and contaminant transport. Information on the numerous amounts of studies conducted here is readily available. This aquifer is relatively simple, and is used as a case study in building this model. MODFLOW2005 is used with its contaminant transport package MT3D-USGS to simulate how chloride and carbon-tetrachloride plumes move within the aquifer, proving that these programs are effective in modeling this type of simple aquifer. 


\subsection{REFERENCES}

Bakker, M., Post, V., Langevin, C. D., Hughes, J. D., White, J. T., Starn, J. J., \& Fienen, M. N. (2016). Scripting MODFLOW Model Development Using Python and FloPy. Groundwater, 54(5), 733-739. doi:10.1111/gwat.12413

Bedekar, V., Morway, E. D., Langevin, C. D., \& Tonkin, M. J. (2016). MT3D-USGS version 1: A U.S. Geological Survey release of MT3DMS updated with new and expanded transport capabilities for use with MODFLOW. Techniques and Methods. doi:10.3133/tm6a53

Cherry, J. A., Barker, J. F., Feenstra, S., Gillham, R. W., Mackay, D. M., \& Smyth, D. J. (1996). The Borden Site for Groundwater Contamination Experiments: 1978-1995. Groundwater and Subsurface Remediation, 101-127. doi:10.1007/978-3-642-45750-0_7

Dance, J., \& Reardon, E. (1983). Migration of contaminants in groundwater at a landfill: A case study. Journal of Hydrology, 63(1-2), 109-130. doi:10.1016/0022-1694(83)90225-1

Egboka, B., Cherry, J., Farvolden, R., \& Frind, E. (1983). Migration of contaminants in groundwater at a landfill: A case study. Journal of Hydrology, 63(1-2), 51-80. doi:10.1016/00221694(83)90223-8

Freyberg, D. L. (1986). A natural gradient experiment on solute transport in a sand aquifer: 2. Spatial moments and the advection and dispersion of nonreactive tracers. Water Resources Research, 22(13), 2031-2046. doi:10.1029/wr022i013p02031

Freeze, R. Allan., and John A. Cherry. Groundwater. Prentice-Hall, 1982.

Harbaugh, Arlen W. MODFLOW-2005: the U.S. Geological Survey Modular Ground-Water Model--the Ground-Water Flow Process. U.S. Geological Survey, 2005.

Johnson, G. R., Zhang, Z., \& Brusseau, M. L. (2003). Characterizing and quantifying the impact of immiscible-liquid dissolution and nonlinear, rate-limited sorption/desorption on lowconcentration elution tailing. Water Resources Research, 39(5). doi:10.1029/2002wr001435

Liu, X., Schnell, S. K., Simon, J., Bedeaux, D., Kjelstrup, S., Bardow, A., \& Vlugt, T. J. (2012). Correction to "Fick Diffusion Coefficients of Liquid Mixtures Directly Obtained from Equilibrium Molecular Dynamics". The Journal of Physical Chemistry B, 116(20), 6070-6070. doi:10.1021/jp3039835

Mackay, D. M., Freyberg, D. L., Roberts, P. V., \& Cherry, J. A. (1986). A natural gradient experiment on solute transport in a sand aquifer: 1. Approach and overview of plume movement. Water Resources Research, 22(13), 2017-2029. doi:10.1029/wr022i013p02017

Macfarlane, D., Cherry, J., Gillham, R., \& Sudicky, E. (1983). Migration of contaminants in groundwater at a landfill: A case study. Journal of Hydrology, 63(1-2), 1-29. doi:10.1016/00221694(83)90221-4 
Paradis, D., \& Lefebvre, R. (2013). Single-well interference slug tests to assess the vertical hydraulic conductivity of unconsolidated aquifers. Journal of Hydrology, 478, 102-118. doi:10.1016/j.jhydrol.2012.11.047

Sudicky, E., Cherry, J., \& Frind, E. (1983). Migration of contaminants in groundwater at a landfill: A case study. Journal of Hydrology, 63(1-2), 81-108. doi:10.1016/0022-1694(83)90224-x

Wellman, D. M., Riley, R. G., Parker, K. E., \& Mitroshkov, A. V. (2006). Adsorption of Carbon Tetrachloride to Sediments from the UP-1 Operable Unit. doi:10.2172/936770

Zheng, Chunmiao, and P. P. Wang. MT3DMS: A Modular Three-Dimensional Multispecies Transport Model for Simulation of Advection, Dispersion, and Chemical Reactions of Contaminants in Groundwater Systems; Documentation and Users Guide. Defense Technical Information Center, 1999. 


\subsection{APPENDIX}

This section includes a tutorial on how to create the base model used in this project. The base model can then be used to further evaluate the impact of changing input parameters on the final results. Also, improvements to this base model could be made to more accurately model this system.

\section{Downloading required applications}

1. Download Modflow 2005

a. https://water.usgs.gov/ogw/modflow/mf2005.html

2. Download MT3D-USGS

a. https://water.usgs.gov/ogw/mt3d-usgs/

3. Download Model Muse

a. https://water.usgs.gov/nrp/gwsoftware/ModelMuse/ModelMuse.html

4. Make sure to note where all of these are saved, as the executables within each will have to be linked to ModelMuse in order to run simulations 


\section{Creating base model}

1. Before we can run any simulations, Model Muse must know the locations of the actual program 'Modflow 2005,' and the contaminant transport package 'MT3D-USGS.' Click on the 'Model' tab and select 'MODFLOW Program Locations'

a. Under Modflow 2005, navigate to the folder containing the executable

b. Under MT3D-USGS, navigate to the folder containing the executable

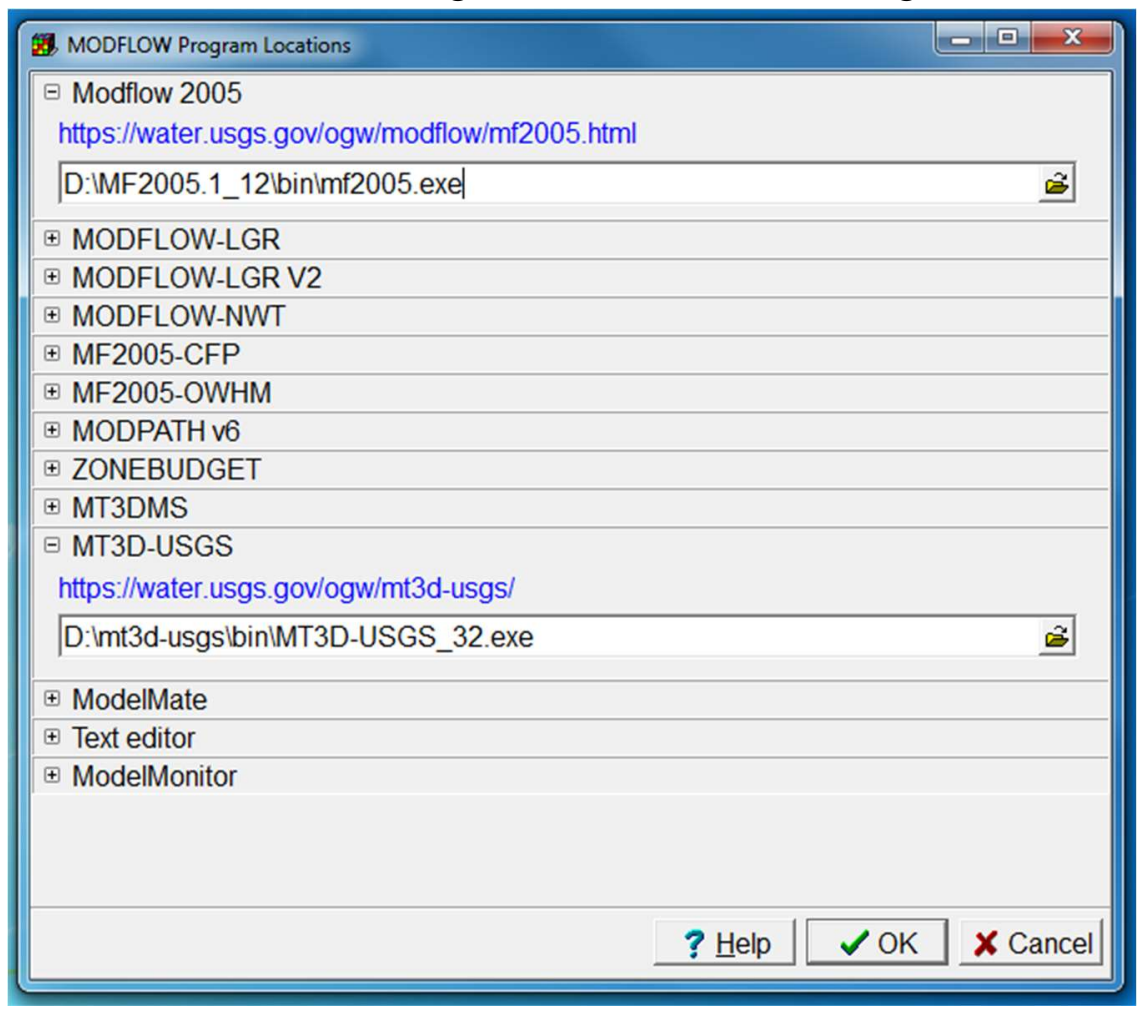

\section{Discretizing Grid}

2. Open Model Muse and select 'Create New Model'

3. Fill in initial grid with overall properties of area you will be looking at (this can be changed later)

4. The user can also import an image to build a base model on

a. Once an image is imported, the grid is created by selecting points on the boundaries and assigning corresponding ' $x$ ' and ' $y$ ' coordinates 


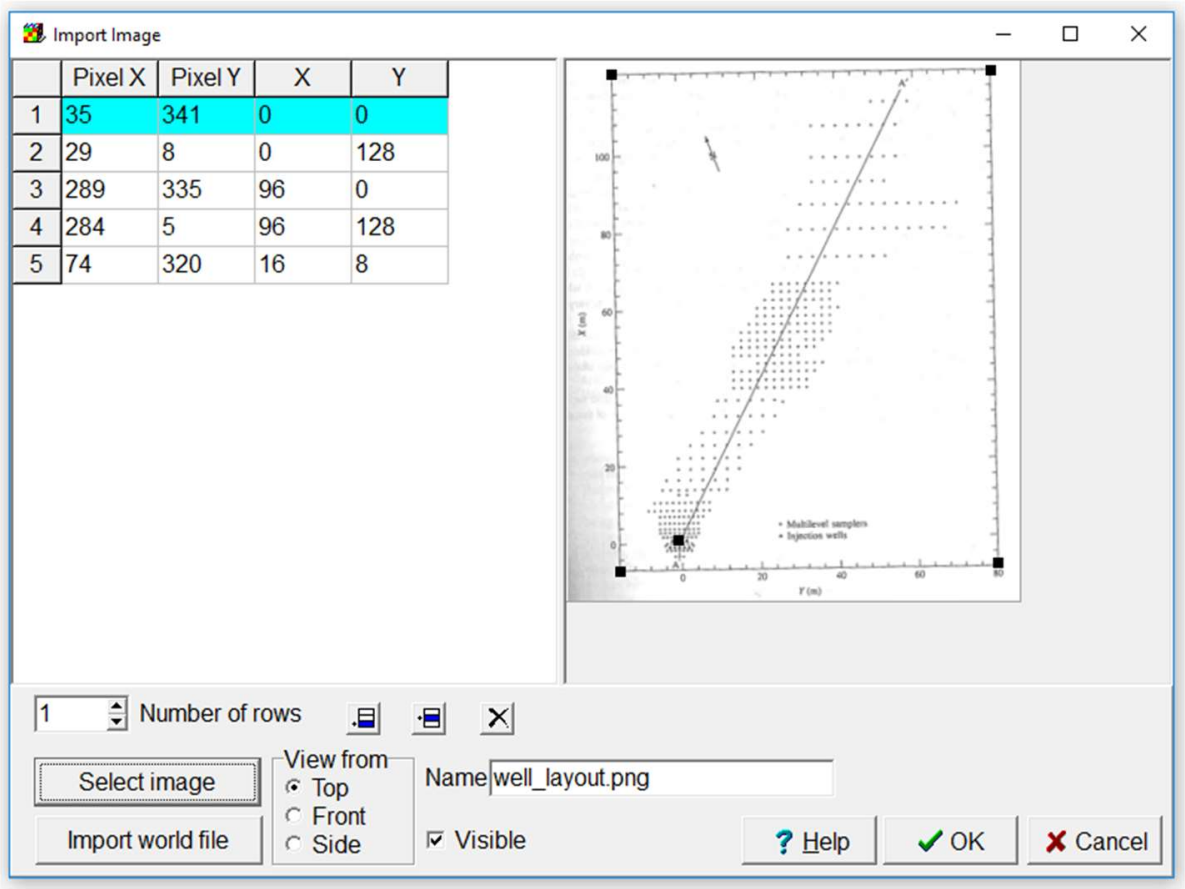

5. Select the Create Object button $\square$ and draw an image around the area you are interested in discritizing

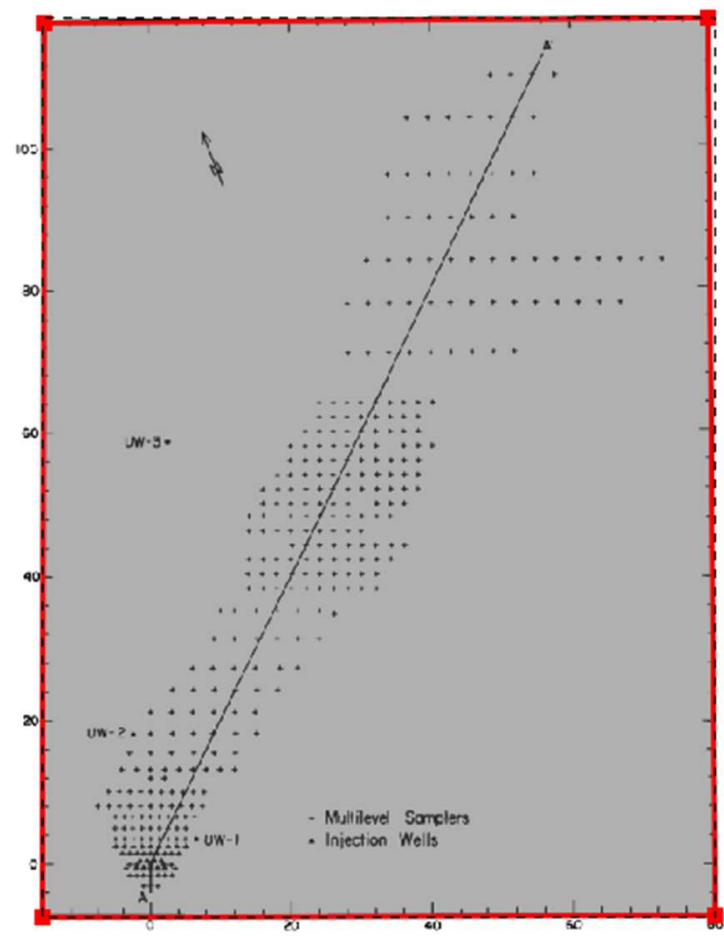

6. Select the Generate Grid button 凅 and select the object previously created. This will create a grid on the system of interest 


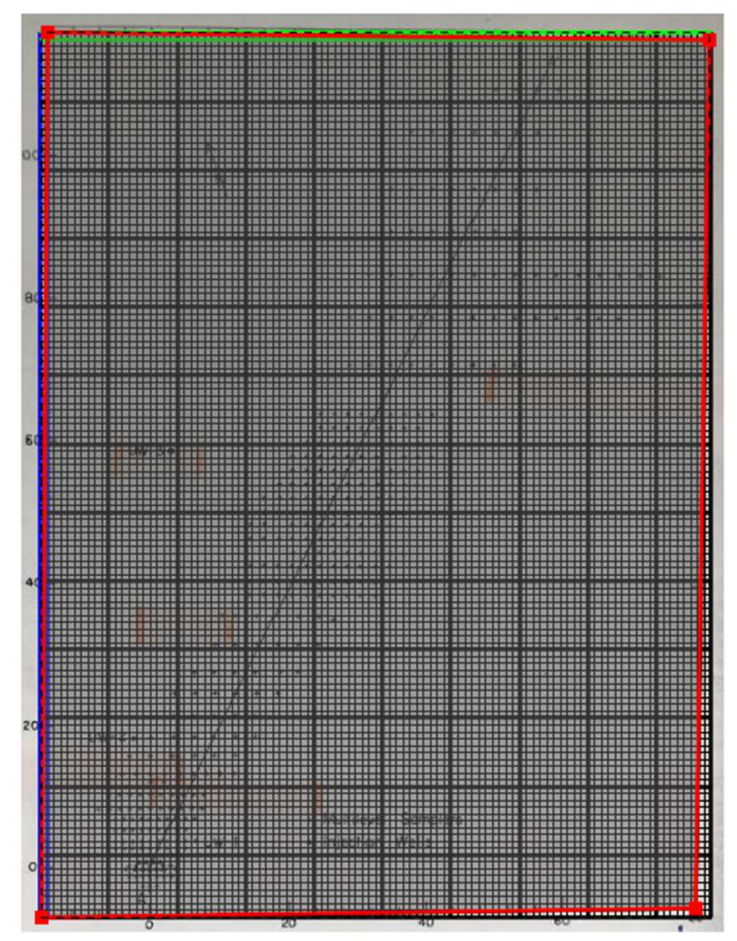

7. Assigning hydraulic conductivity to each layer

a. Data $>$ Edit Data Sets

b. Under the hydrology tab, the hydraulic conductivity in the $\mathrm{x}, \mathrm{y}$, and $\mathrm{z}$ direction can be defined

i. To define a different $\mathrm{Kh}$ at each layer, use the formula below

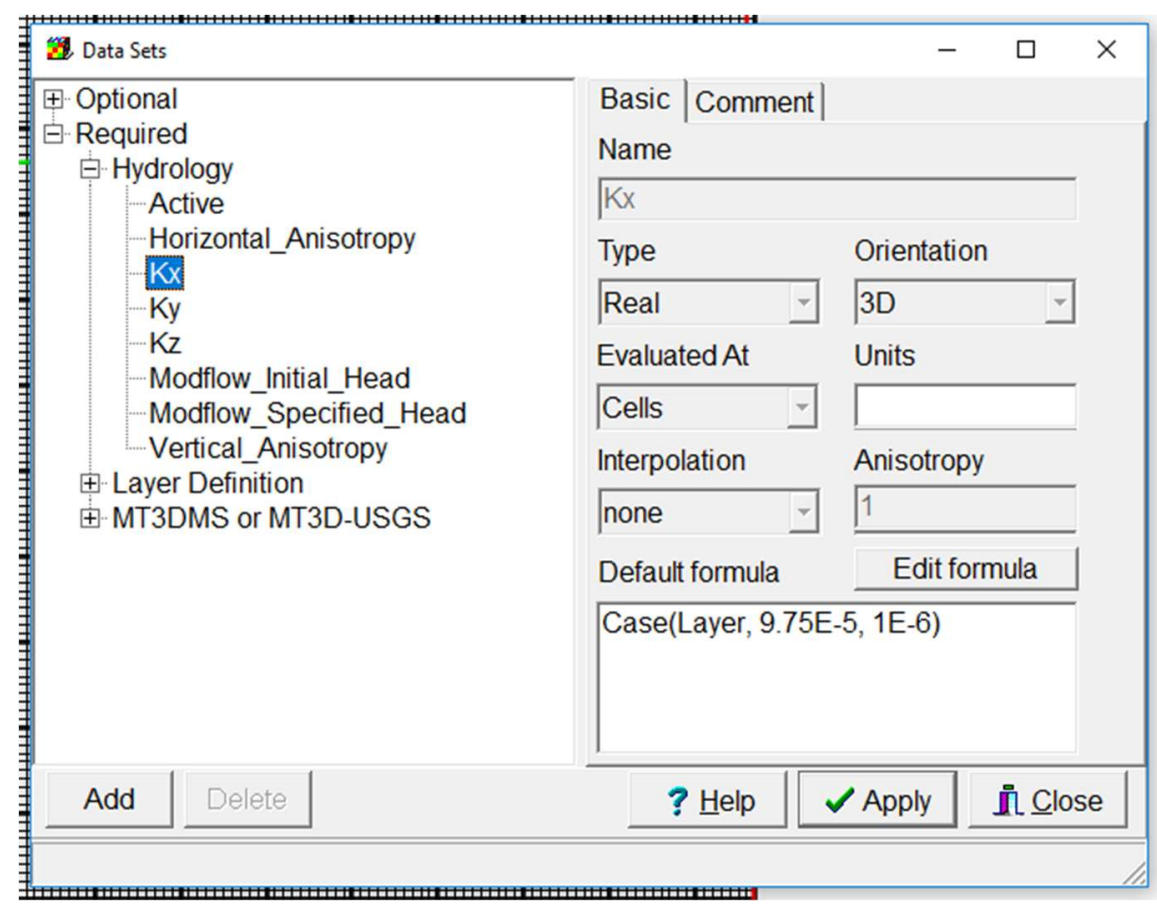


8. Assigning time period

a. Go to Model > MODFLOW Time

b. Steady state rather than transient state

c. Study was done over the course of 3 years, results of contaminant transport were in 2 years so $63,072,000$ seconds will be the total time period in the simulation

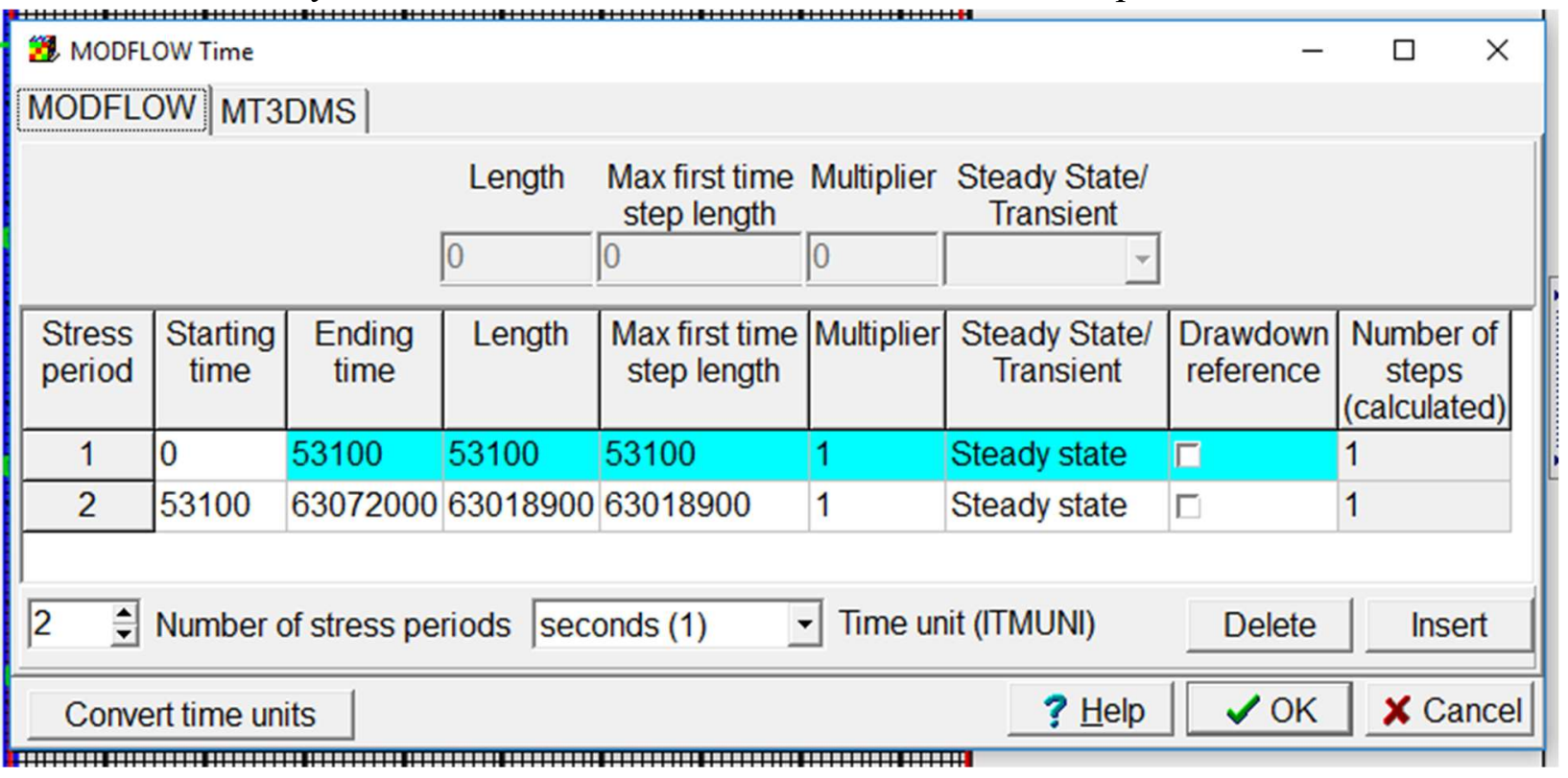

9. Activating Packages

a. Go to Model $>$ MODFLOW Packages and Programs

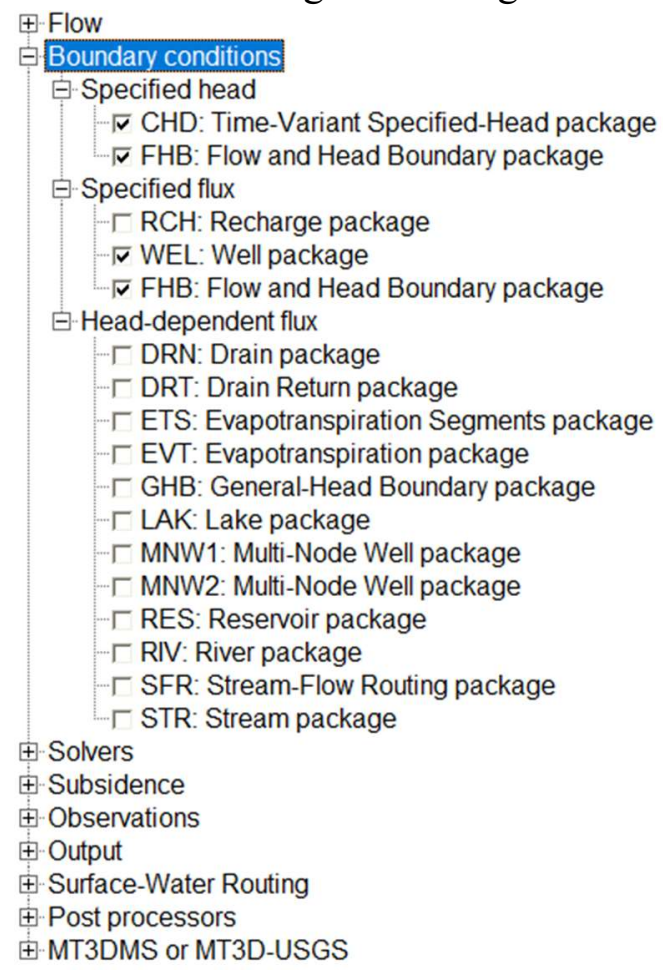

b. These packages allow us to specify head at a boundary and insert wells 
10. Specifying head conditions

a. CHD package

b. Create objects, specify any that are creating a boundary condition under MODFLOW features as the CHD package

c. Specify the starting and ending times, as well as starting and ending heads

d. Another image was inserted containing equipotential lines from a water table map. Using these equipotential lines, and object is created by tracing one of the equipotential lines as shown below:

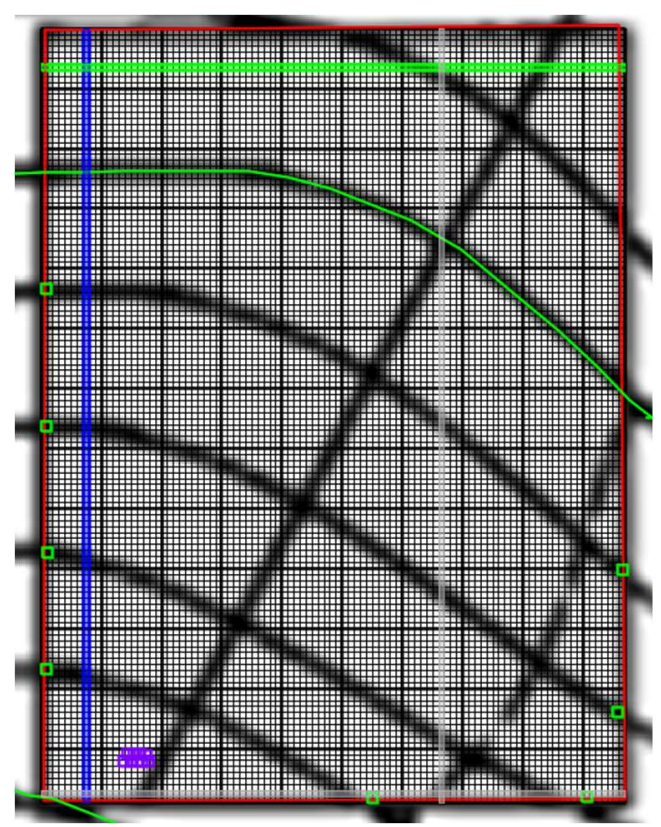

e. Double click on this object and define it as part of the CHD package (this is an initial head condition)

i. The starting time and ending time, with its associated starting and ending head is specified 


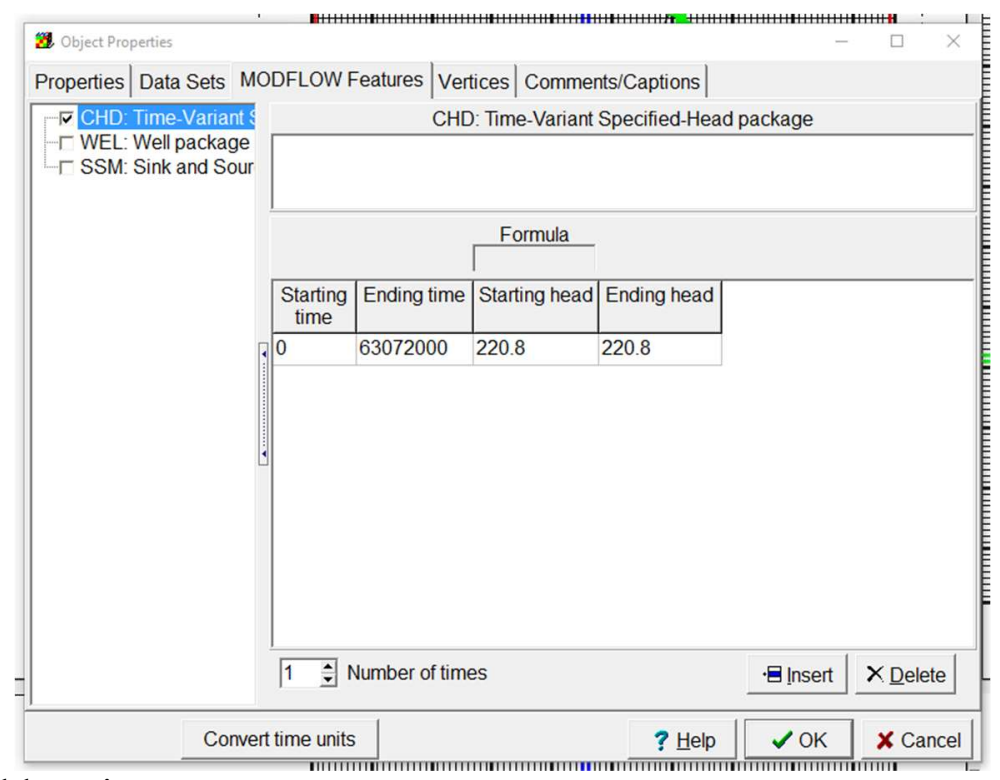

\section{Import well locations}

a. Activate the WEL Package

b. Create point where the injection well is located and under the features tab designate it as a well, select start and end time, and change pumping rate if needed

i. A positive pumping rate indicates fluid entering the system

ii. A negative pumping rate indicates fluid leaving the system

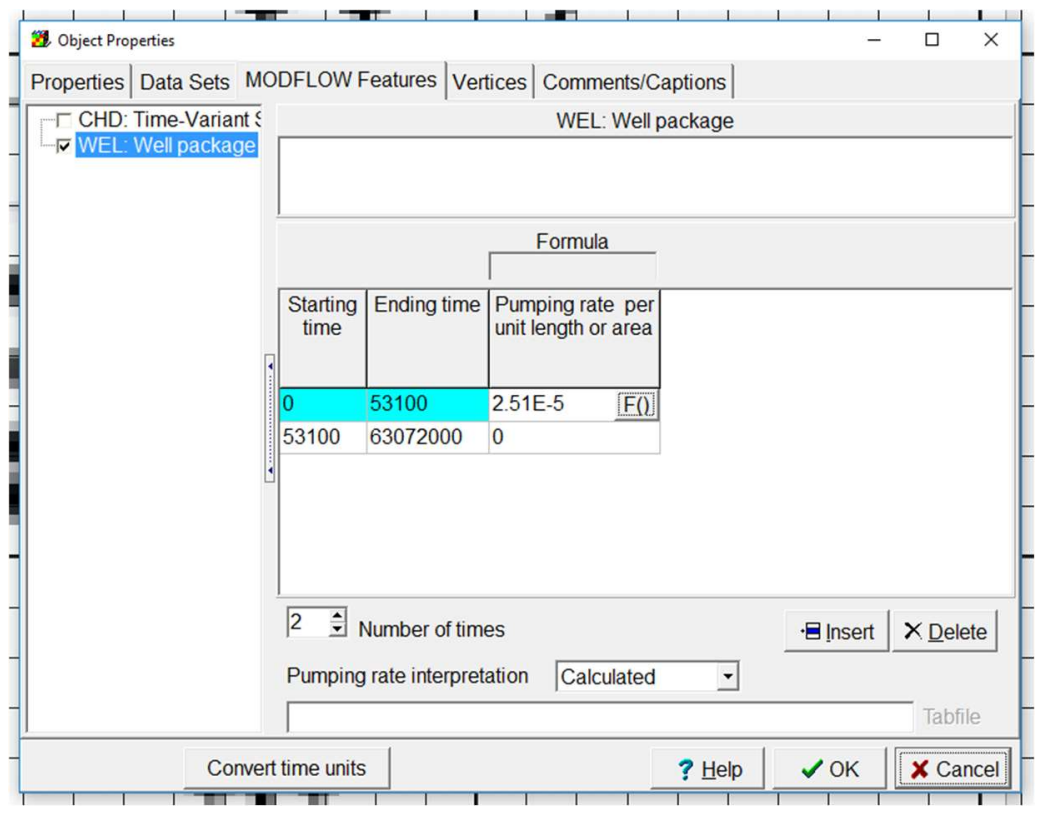

\section{Run MODFLOW}

a. Push the play button 
b. If you get an error about initial head being at or below bottom of layer, change initial head value to the Model_Top

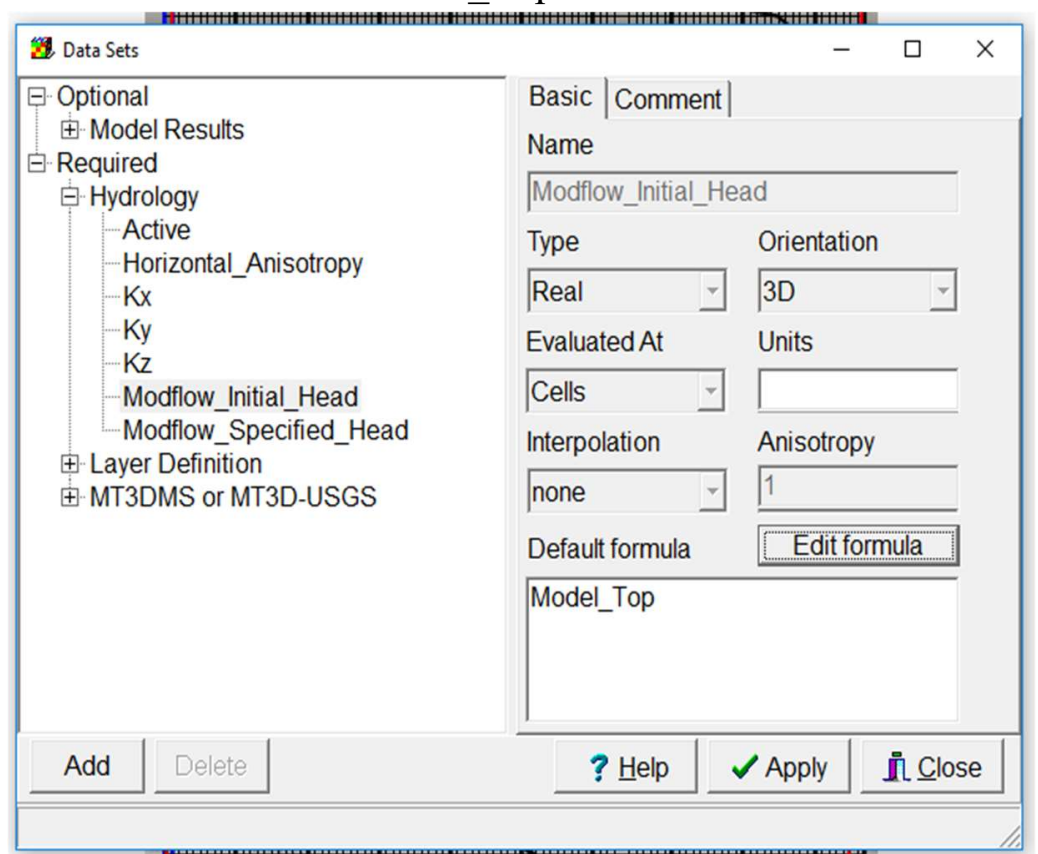

c. Go to File, Import, Model Results

d. Select the .fhd file (this is the head distribution file)

e. Results should look like below

f. Select the Data Visualization button to change the color scheme, and to view the legend 


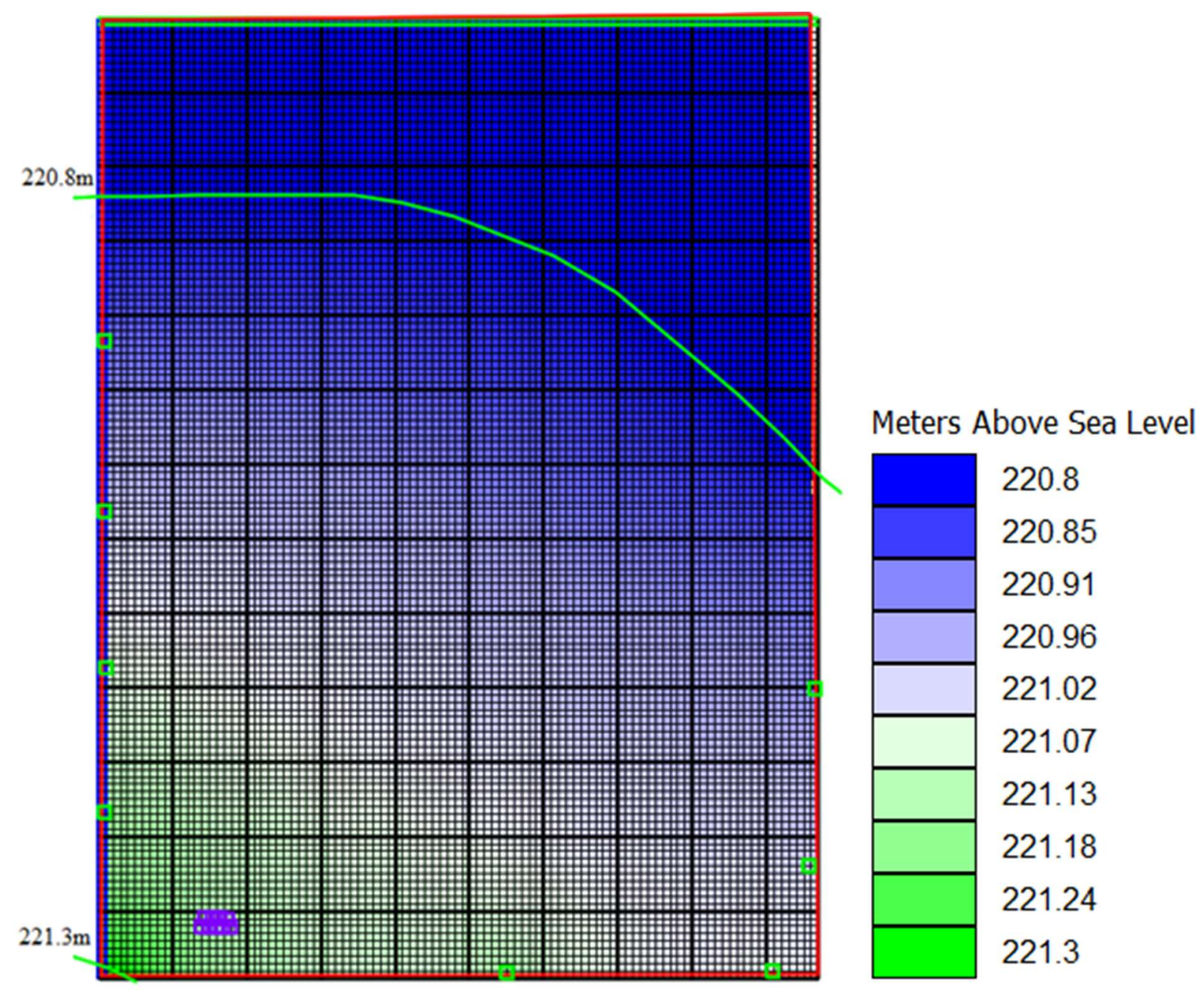

13. Activating MT3D-USGS

a. Use the process as outlined above to activate the contaminant transport package

b. Within the MODFLOW Packages and Programs tab, then select the following packages to activate

i. BTN (Basic Transport)

ii. ADV (Advection)

iii. DSP (Dispersion)

iv. SSM (Source and Sink Mixing) 


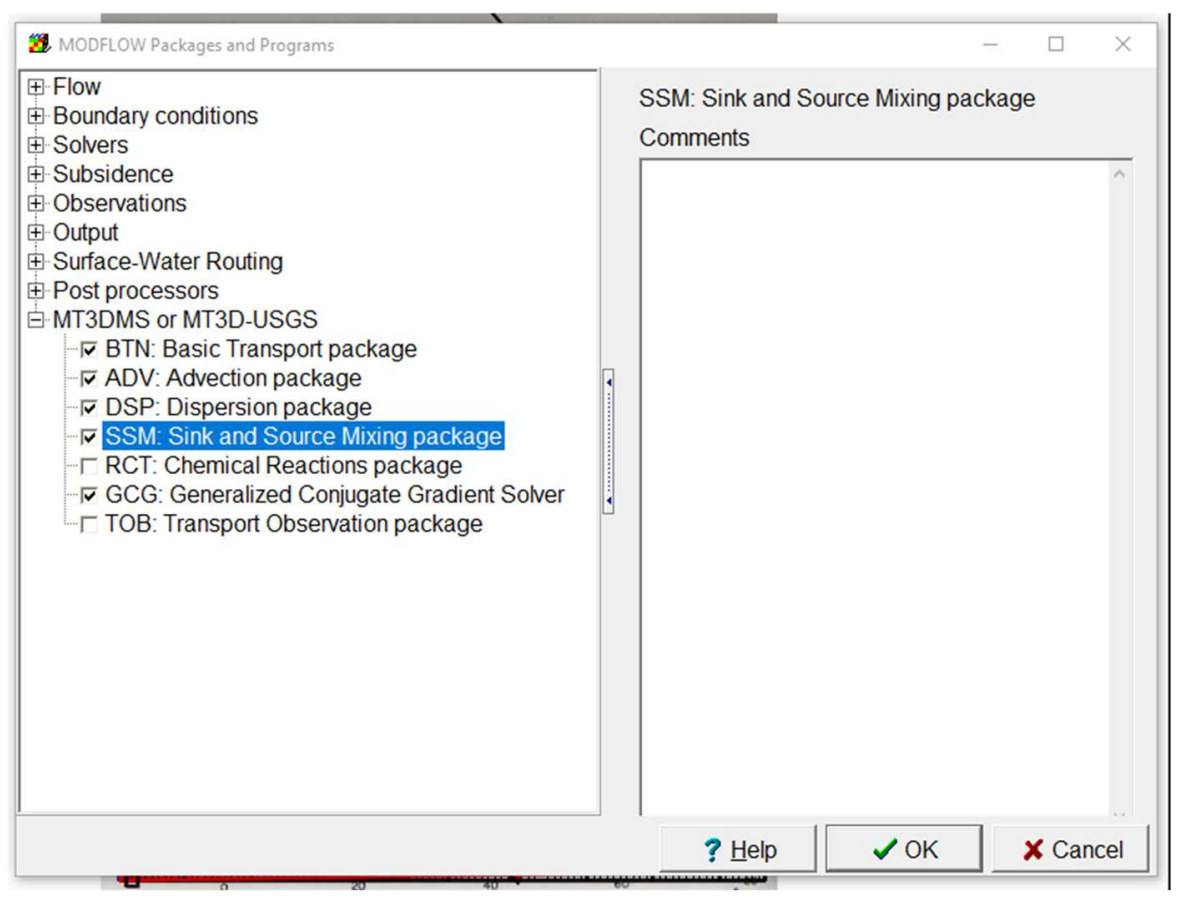

14. Designate data needed for MT3D-USGS package, part of Basic Transport Package

a. Define the name of the species of interest

b. Set the initial concentrations of those constituents in the background water

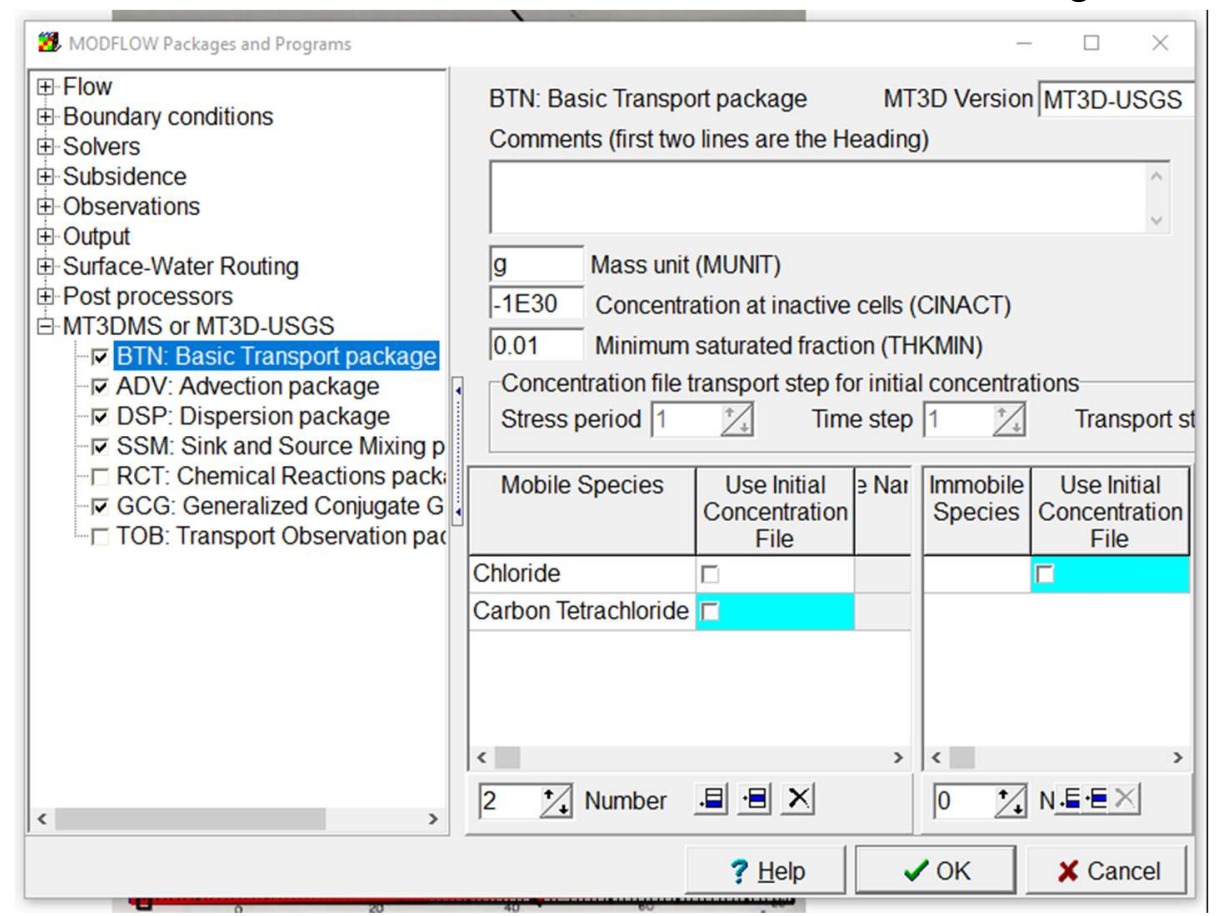

c. Go to Data > Edit Data Sets

i. Within the MT3D-USGS dropdown menu, the porosity of the system can be defined 


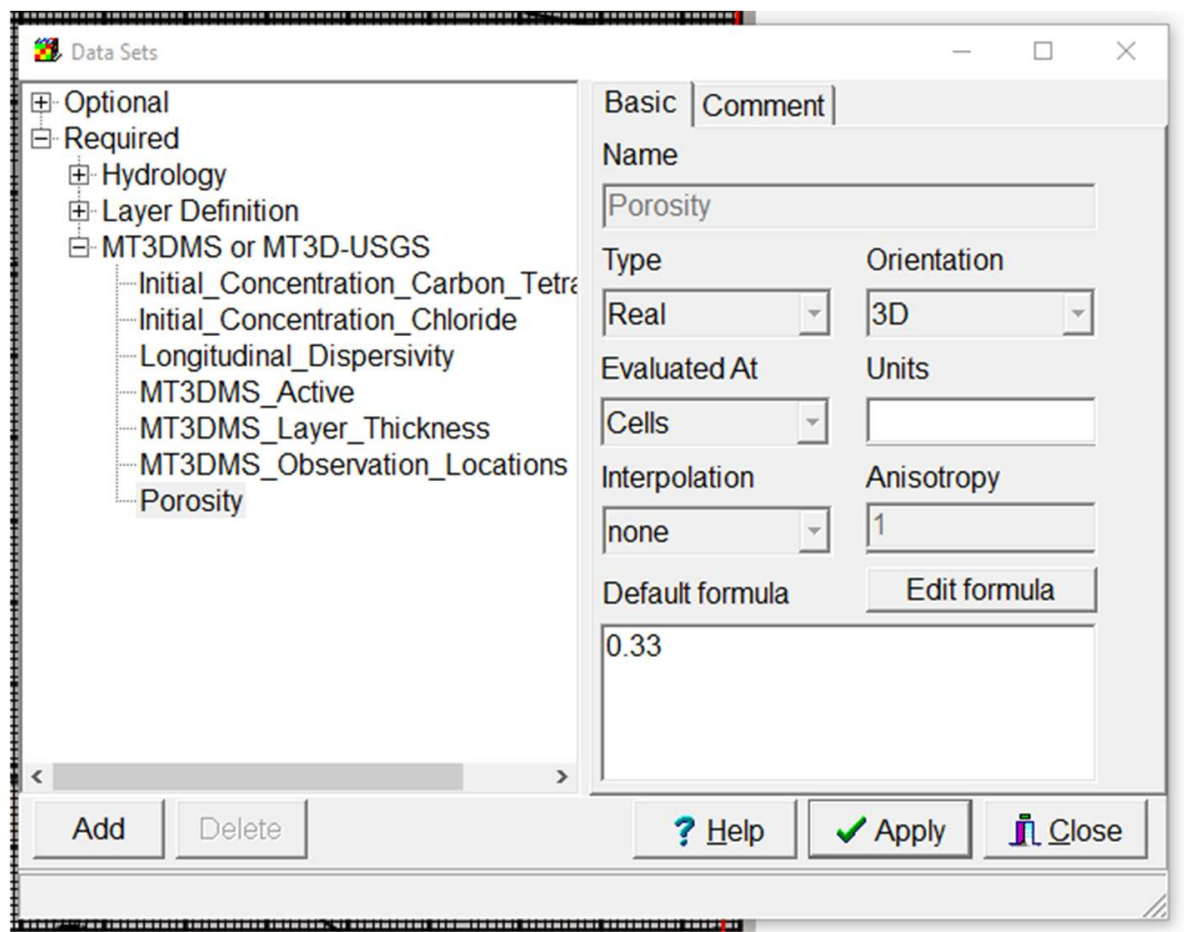

d. Make sure layers are active

15. Make sure advection package is selected, this is how the contaminant moves with the dominant fluid flow based off the base model simulating groundwater flow

16. Select the dispersion package and specify the following

a. $\quad$ Edit $>$ Data Set

i. Under the MT3D-USGS tab, the longitudinal dispersivity can be defined

b. Dispersion tab is added into each layer group

c. Go to Model > MODFLOW Layer Group

i. Set horizontal transverse dispersivity within each layer

ii. Set vertical transverse dispersivity within each layer

iii. Set diffusion coefficient within each layer 


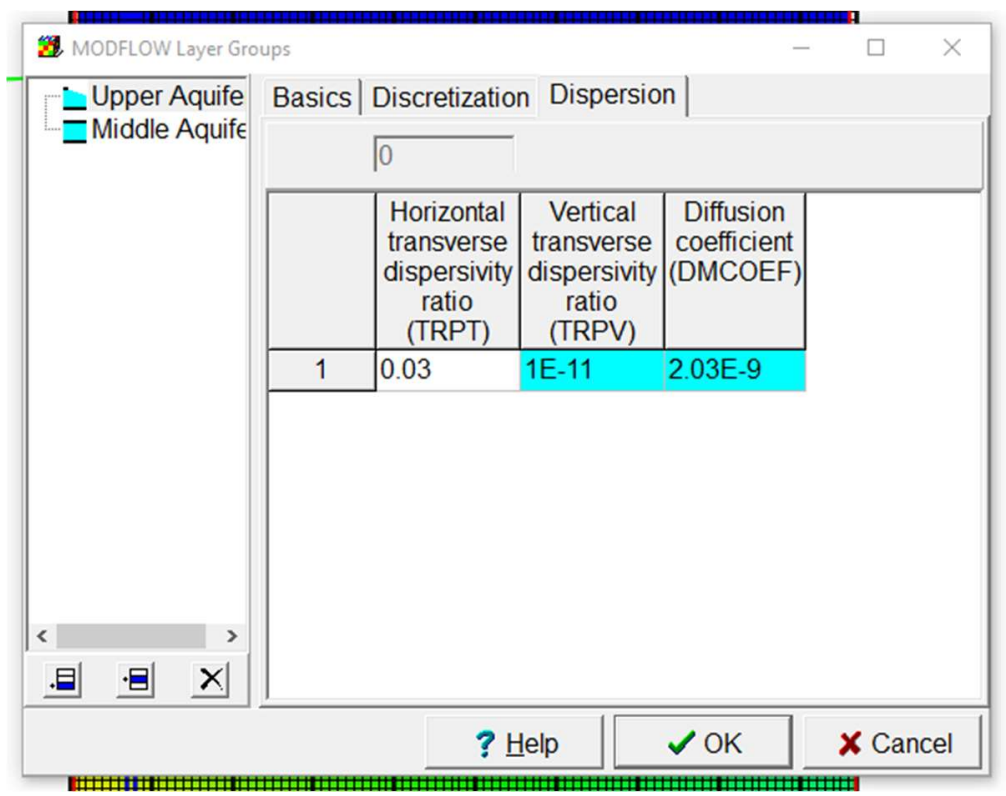

17. Turn on source/sink mixing package

a. Select each well and turn on the SSM package for that well

b. Designate the mass loading or concentration for each for each stress period

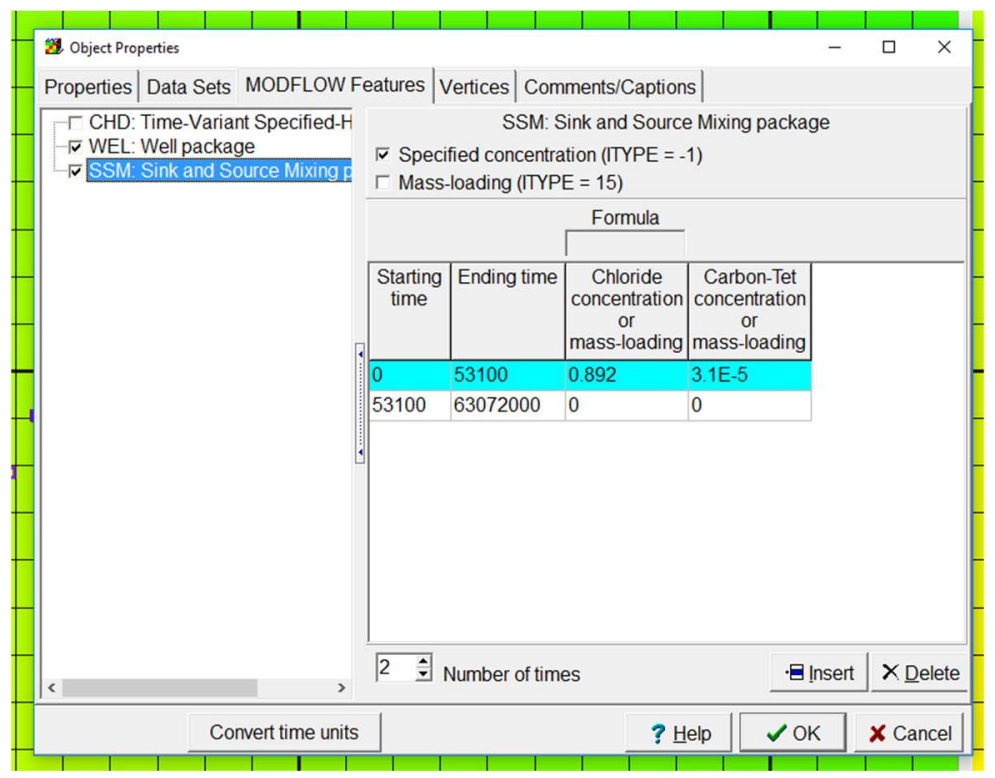

18. Turn on reaction package

a. $\quad$ Edit $>$ Data Sets

i. Under the MT3D-USGS tab define bulk density

b. Sorption parameters for each contaminant

i. Sorption parameter 1 for each contaminant is equal to the $\mathrm{Kd}$ for that contaminant

ii. Sorption parameter 2 would be altered if a modeling technique such as Freundlich was used to model sorption 


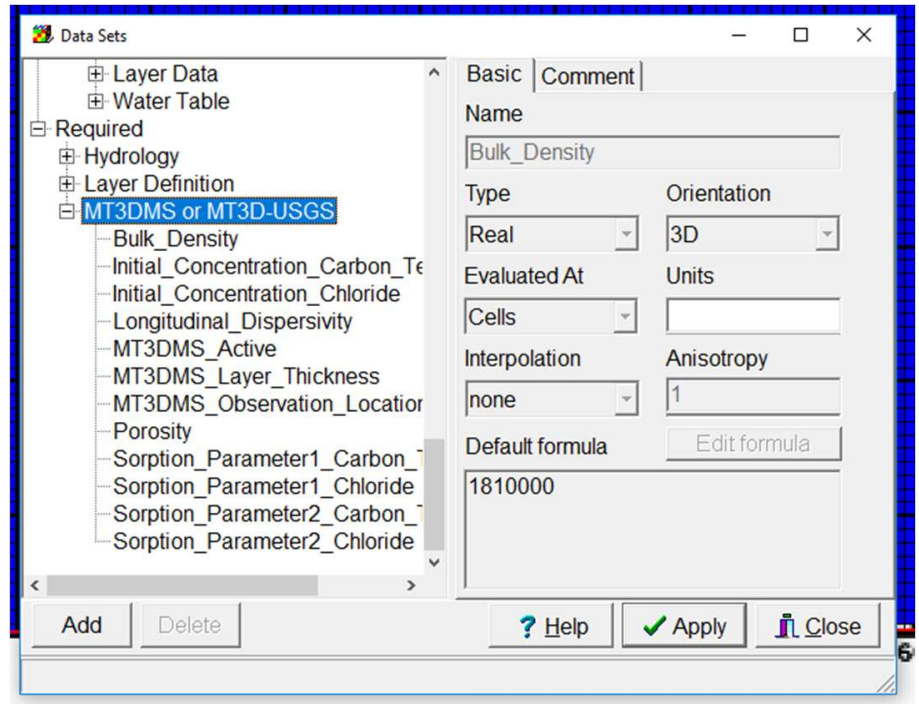

19. Running contaminant transport simulation

a. Change frequency of transport steps

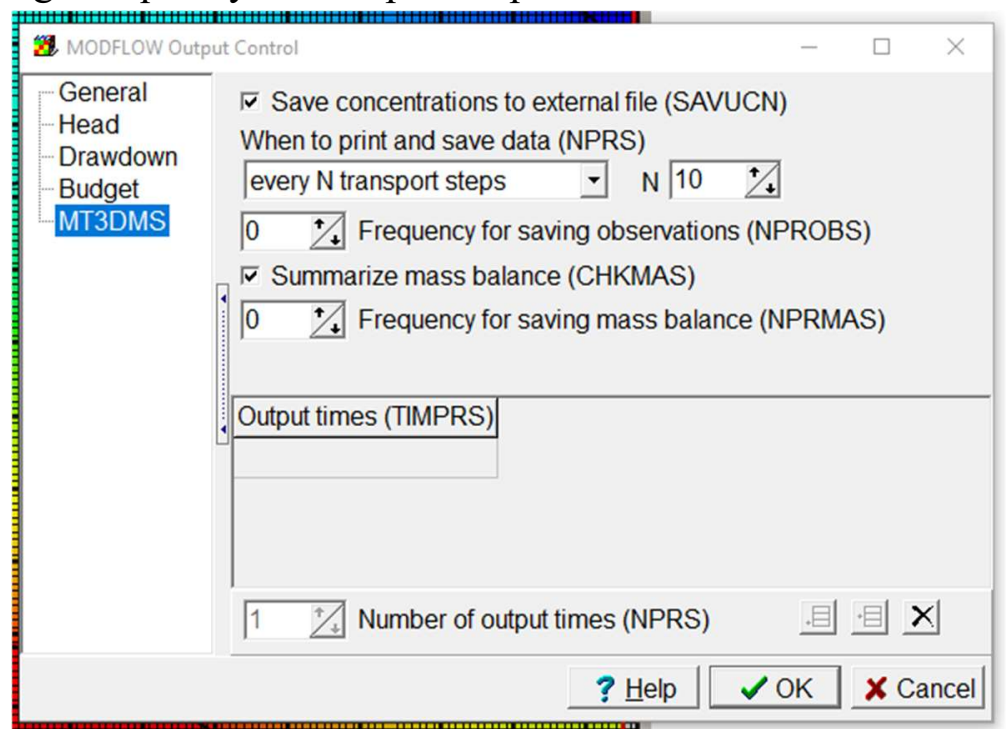

b. Export MT3DMS input files

c. Once program has completed run, go to file, import model results and select the .ucn file of the solute in which you are interested in

20. Visual results should now be available on your grid

a. Further analysis can now be done by changing your input parameters, or adding to the model to improve the desired results 